\title{
Heat budget in the North Atlantic subpolar gyre: impacts of atmospheric weather regimes on the 1995 warming event
}

\author{
Barrier Nicolas $^{1,4, *}$, Deshayes Julie ${ }^{1,2,4}$, Treguier Anne-Marie ${ }^{1,4}$, Cassou Christophe ${ }^{3}$ \\ ${ }^{1}$ Laboratoire de Physique des Oceans, UMR 6523, CNRS/IFREMER/IRD/UBO, Brest, France \\ 2 ICEMASA, Department of Oceanography, University of Cape Town, South Africa \\ ${ }^{3}$ CNRS-CERFACS, Toulouse, France \\ * Corresponding author : Nicolas Barrier
}

\begin{abstract}
:
In the mid 1990's, the North Atlantic subpolar gyre has shown a dramatic warming event that has been thoroughly investigated from observations and numerical simulations. Some studies suggest that it is due to an interannual, wind-driven weakening and shrinking of the gyre that facilitated the penetration of warm Atlantic Water, the weakening of the gyre being attributed to changes in the North Atlantic Oscillation (NAO) and the East Atlantic Pattern, which are the two dominant modes of atmospheric variability in the North Atlantic. However, other studies suggest that the warming event is due to a decadal, buoyancy-driven strengthening of the meridional overturning circulation and subsequent intensification of the poleward heat transport, in response to the positive NAO conditions of 1988-1995. To reconcile this discrepancy, the heat budget in the North Atlantic subpolar gyre is reconstructed from four ocean hindcast simulations sharing the same modelling platform but using different settings. The novelty of this work is the decomposition of the subpolar gyre into a western and an eastern subregion, which is motivated by water mass distribution around Reykjanes Ridge and by the fact that deep convection only occurs in the western subpolar gyre. In the western subpolar gyre, the 1995 warming event is the decadal, baroclinic ocean response to positive NAO conditions from 1988 to 1995 . The latter induced increased surface heat loss in the Labrador Sea that intensified deep convection hence strengthened the meridional overturning circulation and the associated poleward heat transport. In the eastern subregion, a concomittant warming was induced by an interannual, barotropic adjustment of the gyre circulation to an abrupt change from positive to negative NAO conditions in the winter 1995-1996. Indeed, the gyre response to negative NAO conditions is a cyclonic intergyre-gyre which increases northward volume and heat transports at the southeastern limit of subpolar gyre. Therefore, the discrepancies found in the literature about the 1995 warming event of North Atlantic subpolar gyre are reconciled in the present work, which suggests that the atmospheric drivers, the mechanisms at stake and the associated timescales are different to the east and to the west of Reykjanes Ridge.
\end{abstract}




\section{Highlights}

- The mechanisms of the 1995 warming of the subpolar gyre are adressed. Heat budget is performed in the western and eastern subpolar gyre. In the western subpolar gyre, the warming is due to a delayed spin-up of the MOC. In the eastern subpolar gyre, it is due to a fast change in the gyre circulation.

Keywords : Heat content, Subpolar gyre, Nordic Seas, Surface heat fluxes, Heat convergence, Heat transport, Volume transport, North Atlantic Oscillation, Weather regimes, Meridional overturning circulation, Gyre circulation, Baroclinic adjustment, Barotropic adjustment, 1995 warming 


\section{Introduction}

The global increase of ocean heat content (e.g. Levitus et al. 2009) is a critical variable for detecting the effects of the observed increase in greenhouse gases in the Earth's atmosphere (Bindoff et al. 2007). Besides, the accumulation of heat by the ocean induces a thermosteric sea-level rise (Cabanes et al. 2001) that may have disastrous societal impacts (Dasgupta et al. 2009), since it is expected to account for some $70 \%$ of the projected sea-level rise in climate change scenarios (Meehl et al. 2007). However, considering only global heat content and focusing on the warming trends may hide strong regional disparities and temporal fluctuations. This is especially true in the North Atlantic Ocean, which has warmed in the subtropics and cooled at subpolar latitudes between the 20 year periods 1950-1970 and 1980-2000 (Lozier et al. 2008, Zhai and Sheldon 2012). A preliminary step, in order to determine whether these changes can be attributed to the increase in anthropogenic greenhouse gases emission, is to have a good knowledge of the drivers of natural ocean heat content variability.

In the North Atlantic, a significant part of the variability of the ocean circulation is driven by changes in the large-scale atmospheric circulation, either inferred from the traditional modes of variability, such as the North Atlantic Oscillation (Hurrell 1995, NAO hereafter) and the East Atlantic Pattern (Barnston and Livezey 1987), or from the so-called weather regimes (Cassou et al. 2011). These large-scale atmospheric patterns are associated with surface forcing anomalies that impact the ocean circulation at monthly to decadal time scales. The resulting changes in ocean heat convergence, in addition to the anomalous surface heat fluxes associated with these patterns, may cause significant changes in ocean heat content. In particular, changes in the large-scale atmospheric circulation have been proposed to explain the unprecedented warming of the subpolar gyre that occurred in 1995 and that has been thoroughly examined either using observations (Bersch 2002, Bersch et al. 2007, Sarafanov et al. 2008), realistic simulations (Marsh et al. 2008, Lohmann et al. 2009, Grist et al. 2010, Desbruyeres et al. 2014) and decadal prediction experiments (Yeager et al. 2012, Robson et al. 2012, Msadek et al. 2014).

Bersch (2002), Bersch et al. (2007) and Sarafanov et al. (2008) suggest that the abrupt shift in the NAO index between $1995\left(\mathrm{NAO}_{\text {index }}=+1.31^{1}\right)$ and $1996\left(\mathrm{NAO}_{\text {index }}=-1.39^{1}\right)$ lead to a wind-driven weakening and shrinking of the subpolar gyre. This facilitated the northward advection of warm subtropical water into the subpolar gyre (Hátún et al. 2005), hence inducing the warming. A similar mechanism is proposed by Häkkinen et al. (2011a,b), except that they do not attribute the weakening of the subpolar gyre to the NAO but to changes in the East Atlantic Pattern. They suggest that the wind-stress curl anomalies associated with this particular mode project well on the mean position of the gyres and are thus more likely to modulate

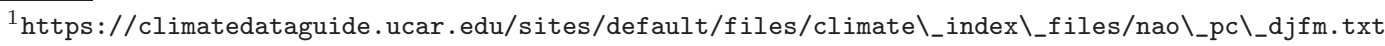


the strength of the horizontal circulation.

Other studies suggest that the warming was due to a delayed, buoyancy-driven ocean response to the highly positive NAO conditions of 1988-1995. This period was characterised by strong surface heat loss in the Labrador Sea, which lead to a strengthening of deep convection and in turn to a strengthening of the meridional overturning circulation (Deshayes and Frankignoul 2008). Using decadal prediction experiments performed in the scope of the fifth phase of the Coupled Model Intercomparison Project (CMIP5, Taylor et al. 2012), Yeager et al. (2012), Robson et al. (2012), Msadek et al. (2014) suggest that this stronger overturning, associated with a stronger northward heat transport, was responsible for the warming of the subpolar gyre that occurred in 1995, while the surface heat fluxes only played a minor role. Lohmann et al. (2009), using model sensitivity experiments, suggest a slightly different mechanism: the stronger meridional overturning circulation lead to an enhanced northward advection of warm subtropical water into the subpolar gyre that counteracted and finally dominated over the local surface heat loss. This ultimately lead to a weakening and in turn to a shrinking of the subpolar gyre that presumably induced the warming.

Hence, although the general consensus is that the 1995 warming of the subpolar gyre has been caused by changes in the large-scale atmospheric circulation, strong uncertainties remain. Which large-scale atmospheric pattern (NAO or East Atlantic Pattern), which time scales (interannual or decadal) and which mechanism (wind-driven or buoyancy-driven changes in ocean circulation) have dominated during the warming of the subpolar gyre? These questions are addressed in the present study using four ocean hindcast simulations, which can be viewed as an ensemble that allows to extract the results that are robust against the model settings (horizontal and vertical resolutions, forcings, parameterisations), as done in Deshayes et al. (2013). For each model simulation, heat budget calculations are performed in the North Atlantic subpolar gyre. A first novelty of the present work is the decompostion of the subpolar gyre into a western and an eastern subregion. Such decomposition is presently unique and is motivated by the fact that deep convection only occurs in the western subpolar gyre (Labrador and Irminger Seas). Furthermore, it is consistent with the water masses distribution around the Reykjanes Ridge (Thierry et al. 2008). In each subregion of the subpolar gyre, the variability of ocean heat convergence and surface heat fluxes, which are the two main contributors to the ocean heat content variability, is linked to the large-scale atmospheric variability at interannual and decadal time scales. Another novelty of the present study is the consideration of the so-called weather regimes as a proxy of the large-scale atmospheric variability, instead of using the traditional climate indices. This choice is motivated by the NAO asymmetry (Cassou et al. 2004), which is evidenced by the weather regime framework and which has been shown to be particularly important when assessing the NAO-driven variability of the gyre circulation (Barrier et al. 2014). 
The paper is organised as follows. In section 2, the ocean hindcast simulations are described. Heat budget calculations are introduced in section 3 and the atmospheric weather regimes are presented in section 4 . In section 5, the variability of ocean heat convergence and surface heat fluxes is linked to the variability of the winter weather regimes at interannual (section 5.1) and decadal (section 5.2) time scales. In section 6, these results are used to understand the causes of the 1995 warming of the subpolar gyre. Conclusion and discussions are provided in section 7 .

\section{Description of the model simulations}

In this study, all the diagnostics are performed on a suite of four ocean hindcasts, which are issued from the Drakkar Project ${ }^{2}$ and which share the "Nucleus for European Modelling of the Ocean" modelling framework (NEMO, Madec 2008). The model simulations all cover the global oceans using the ORCA tripolar grid to avoid the North Pole singularity, as described in Barnier et al. (2006). They are initialized from rest in 1958, with initial temperature and salinities provided by the Levitus et al. (1998) climatology patched with the Polar Science Center Hydrographic Climatology dataset for the Arctic regions. The first seven years of the model simulations are discarded as part of the spin-up, although the deep ocean may not be completely adjusted yet. Still, adjustement of the deep ocean is not expected to dominate the variability in ocean heat content. Indeed, changes in ocean heat content calculated over the upper ocean $(0-700 \mathrm{~m})$ and the full water column are very similar (Desbruyeres et al. 2014).

The "Low-Resolution 1" simulation (LR1 hereafter) has for a long time been considered as the Drakkar reference hindcast. As such, it has been used in a large number of publications (Treguier et al. 2007, Lique et al. 2010, Desbruyeres et al. 2014 among others). It uses the Drakkar Forcing Set version 3 (DFS3), introduced by Brodeau et al. (2010) and constructed from the ERA-40 reanalysis (Uppala et al. 2005) following the methodology of Large and Yeager (2009). This forcing dataset extends from 1958 to 2001.

The "Low-Resolution 2" (LR2) simulation has been described in Lique and Steele (2013). The major differences between LR1 and LR2 are the vertical resolution (75 levels in LR2 instead of 46 in LR1), the salinity restoring (six times weaker in LR2 than in LR1) and the forcing dataset. LR2 uses the Drakkar Forcing Set version 4.3 (DFS4.3), which is constructed from DFS3 by applying a time-dependent recalibration of ERA-40 surface atmospheric fields in the tropical band, a re-adjustments of Arctic air temperature and humidity based on the POLES climatology, a global increase of the wind speed based on QuikSCAT values and zonal adjustments of the downwelling radiation and precipitation, as detailed in Brodeau et al. (2010). This dataset is extended until 2006 by adding the variability of the "European Centre for Medium-Range

\footnotetext{
${ }^{2}$ http://www.drakkar-ocean.eu/
} 
Weather Forecasts" (ECMWF) operational reanalysis fields to the corrected DFS3 means. A drawback of this forcing dataset is that the ECMWF operational reanalysis has a time-evolving resolution and timeadjusted parameterisations that complicate the construction of homogenous forcing dataset.

The "High Resolution" (HR hereafter) simulation, fully described in Molines et al. (2014), is the first long-lasting (55 years) high resolution $\left(1 / 12^{\circ}\right)$ model simulation issued from the Drakkar Project. It is forced with the Drakkar Forcing Set version 4.4 (DFS4.4), which is identical to DFS4.3 from 1958 to 2001. It is extended until 2010 by adding the variability of the ERA-interim reanalysis (Dee et al. 2011) to the corrected DFS3 means. Since ERA-interim is built using a model with constant resolution and parameterisations, it ensures homogenous forcings for the 2002-2010 period.

The "Low-Resolution 3" (LR3) model simulation has exactly the same settings as the model simulation described in Dussin et al. (2012); it uses the same horizontal resolution as both LR simulations, the same salinity restoring as LR1 and the same vertical resolution as LR2. The only difference is the forcing dataset. The model simulation described in Dussin et al. (2012) is forced with DFS4.3 from 1958 to 1988 and switches abruptly to ERA-interim afterward; this results in a noticeable weakening of the meridional overturning circulation that is not realistic. The LR3 model simulation diagnosed here uses the same forcing dataset as the HR simulation (DFS4.4); as such, it can be viewed as a low-resolution counterpart of HR. Note that LR3 is strictly identical to the model simulation of Dussin et al. (2012) for the period 1958-1988, since the forcing datasets used in both simulations are identical during this period.

As detailed in the above and summarized in table 1, the differences among the model simulations are mainly the horizontal and vertical resolutions, the forcing datasets and the parameterisations. Considering these four simulations, which can be viewed as an ensemble, allows to extract the results that are robust against these settings.

\section{Heat budget calculations}

In this section, the methodology used for the heat budget calculations is described. Comparisons of the simulated transports and heat content with observational-based estimates are also provided.

\subsection{Domains and sections}

Heat budget calculations in the subpolar North Atlantic have already been discussed in Marsh et al. (2008), Grist et al. (2010) or Desbruyeres et al. (2014), who suggest that the ocean heat content variability 
Table 1. List of the model simulations used in this study. The horizontal resolution is given at the equator and increases with latitude. Sea-surface salinity (SSS) restoring coefficients are provided in mm/day.

\begin{tabular}{|c|c|c|c|c|c|}
\hline Name & \multicolumn{2}{|c|}{ Drakkar nomenclature } & Period considered & Forcings & Horizontal resolution \\
\hline LR1 & \multicolumn{2}{|c|}{ ORCA025.L46-G70 } & 1964-2004 & DFS3 & $1 / 4^{\circ}$ \\
\hline LR2 & \multicolumn{2}{|c|}{ ORCA025.L75-G85 } & $1964-2007$ & DFS4.3 & $1 / 4^{\circ}$ \\
\hline LR3 & \multicolumn{2}{|c|}{ ORCA025.L75-GRD88 } & $1964-2010$ & DFS4.4 & $1 / 4^{\circ}$ \\
\hline \multirow[t]{6}{*}{$\mathrm{HR}$} & \multicolumn{2}{|c|}{ ORCA12.L46-MJM88 } & 1964-2009 & DFS4.4 & $1 / 12^{\circ}$ \\
\hline & Name & Vertical levels & SSS restoring & Refer & ence \\
\hline & LR1 & 46 & 167 & Treguier et & al. $(2007)$ \\
\hline & LR2 & 75 & 27 & Lique and $\mathrm{S}$ & teele (2013) \\
\hline & LR3 & 75 & 167 & Dussin et & al. (2012) \\
\hline & $\mathrm{HR}$ & 46 & 167 & Molines et & al. $(2014)$ \\
\hline
\end{tabular}

is dominated by the ocean heat convergence, with the surface heat fluxes playing only a minor damping role. However, the domains considered by these three studies either exclude (Marsh et al. 2008, Desbruyeres et al. 2014) or only partially cover (Grist et al. 2010) the regions where the standard deviation of surface heat fluxes is the strongest (figure 1), hence where the surface heat fluxes are the most likely to impact significantly ocean heat content variability.

As an alternative, a new decomposition is proposed in the present study (figure 2): the subpolar gyre is decomposed into a western and an eastern subregion. The western subregion (hereafter West) is limited in the northwest by two sections across the Hudson strait and Davis strait, by the Denmark Strait Overflow section to the north (labelled DSO in the following) and by a section that goes from Iceland to $52.5^{\circ} \mathrm{N}$ $35.5^{\circ} \mathrm{W}$ (point $\mathrm{P}$ in figure 2) following the Reykjanes/Mid-Atlantic Ridge (MAR hereafter). The section that links P and Newfoundland closes the domain to the south (SSW section). This subregion encompasses the Labrador Sea and the Irminger Basin, where deep convection occurs.

The eastern subregion (hereafter East) has a volume approximately 1.8 times smaller than the western subregion and is limited to the northeast by the Iceland-Faroe Overflow and Faroe-Scotland Overflow sections (IFO and FSO sections, respectively), to the west by the MAR section and to the south by a zonal section that goes from P to Ireland (SSE section). The southern limits of both subpolar subregions (SSE and SSW sections) are somehow arbitrary, since they do not rely on any physical barriers. They have been chosen to avoid the recirculation of the subtropical gyre. Such decomposition of the subpolar gyre is 


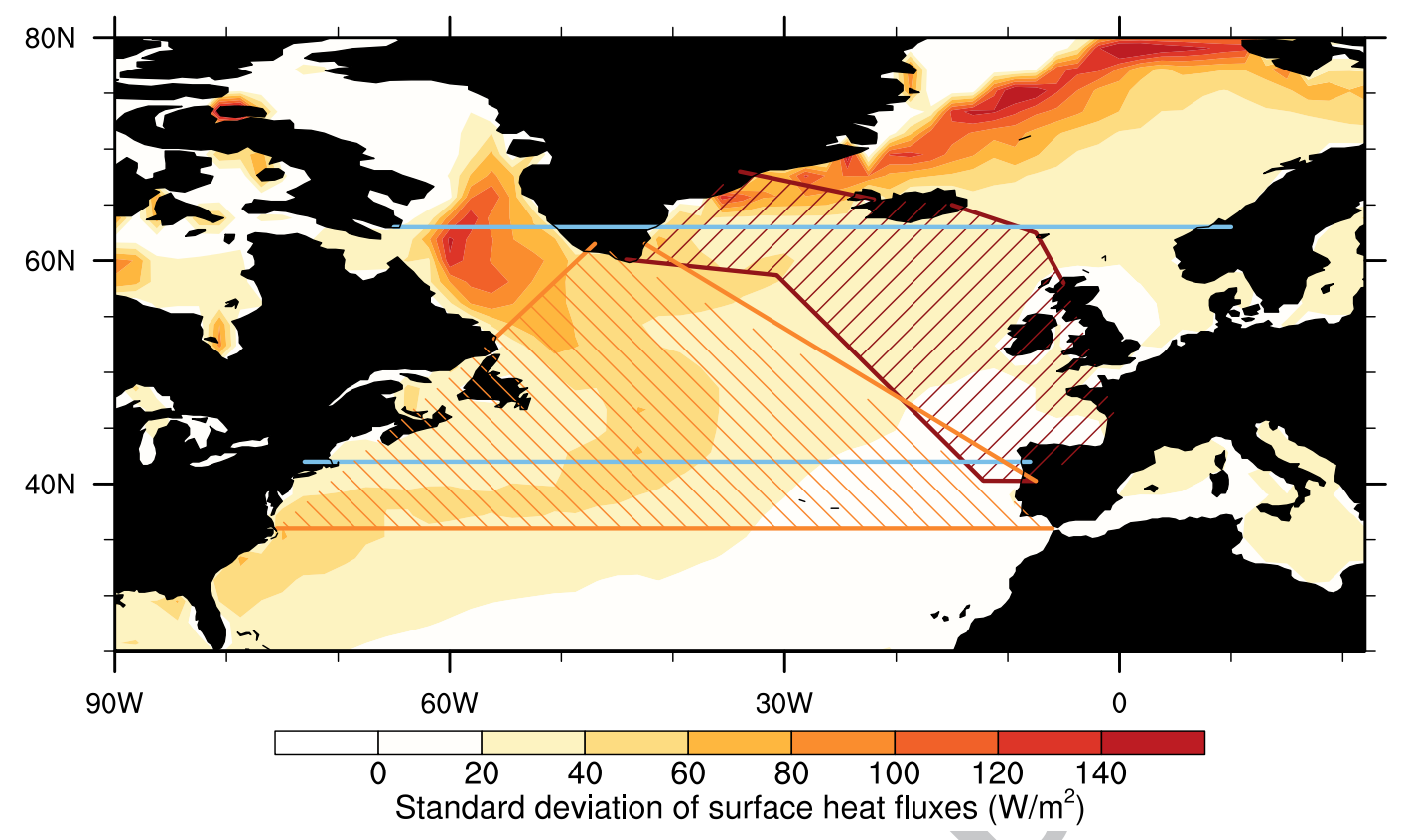

Figure 1. Standard deviation of winter averaged heat fluxes (latent+sensible+longwave+shortwave) determined from NCEP/NCAR reanalysis (Kalnay et al. 1996). Brown and orange hatchings represent the domain considered in Desbruyeres et al. (2014) and Marsh et al. (2008), respectively. The domain considered by Grist et al. (2010) is confined between the two zonal sections $\left(42^{\circ} \mathrm{N}\right.$ and $\left.63^{\circ} \mathrm{N}\right)$ depicted in blue.

presently unique. It preserves the contrast in water mass characteristics in between the two sides of the Reykjanes Ridge, as discussed by Thierry et al. (2008). Furthermore, since the variance of surface heat fluxes is stronger in the western subregion than in the eastern one (figure 1), surface heat fluxes are expected to contribute differently to the heat content variability of each region.

\subsection{Methodology}

Since the four model configurations considered here use a linearized free surface approximation (Roullet and Madec 2000), heat content $\left(h_{c}\right)$ within a closed water volume $V$ (either the western or eastern subpolar gyre, figure 2) is given by:

$$
h_{c}=\rho_{0} C_{p}\left(\iiint_{V} T d x d y d z+\iint_{S_{a}} S S T \eta d x d y\right)
$$

with $\rho_{0}$ and $C_{p}$ the reference density and heat capacity of sea-water, $T$ the three-dimensional temperature, $S_{a}$ the surface of the water volume $V$ that is in contact with the atmosphere, $S S T$ and $\eta$ the sea-surface temperature and sea-surface height. 


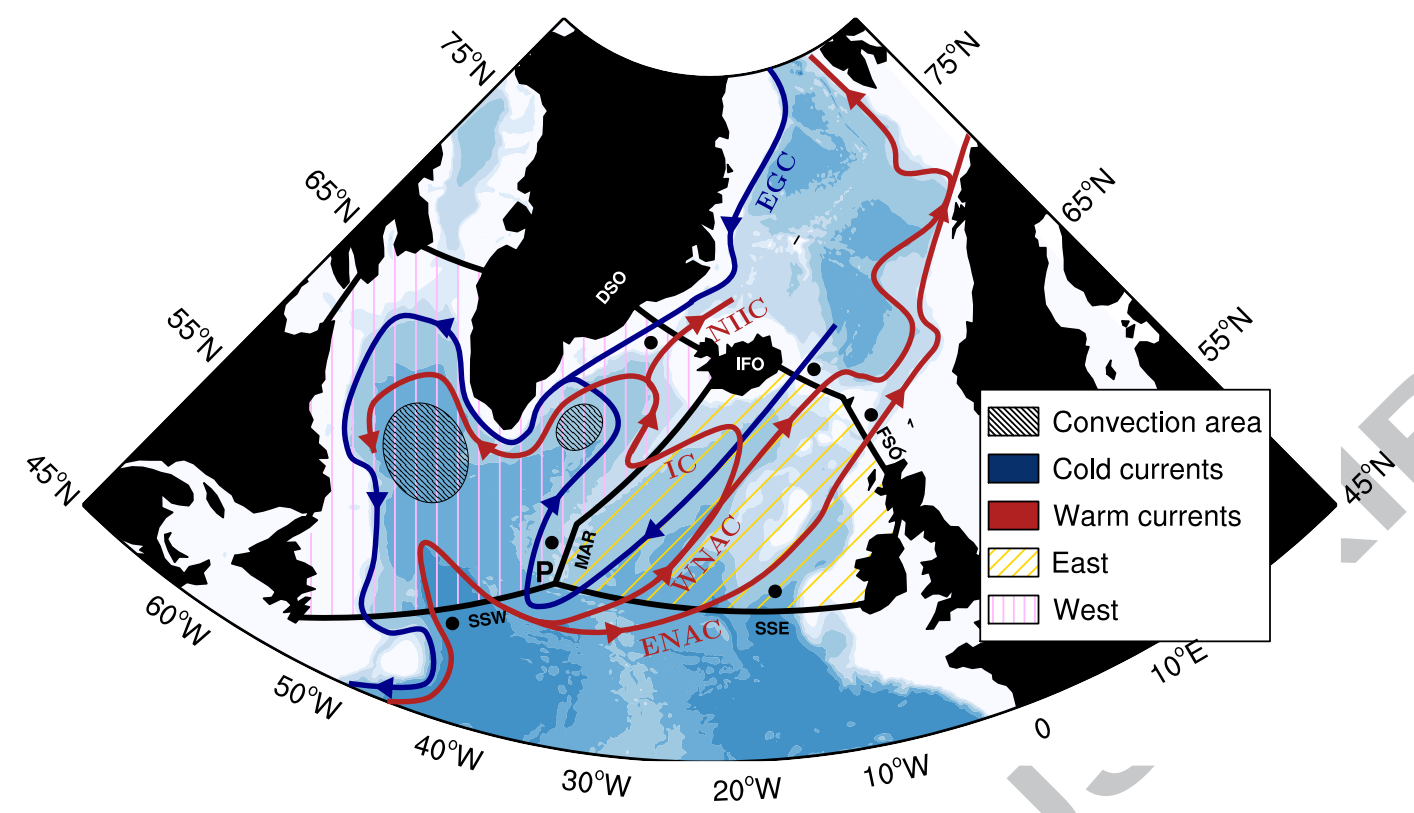

Figure 2. Subregions and sections considered in the present work. Black points indicate the orientation of the sections (transport is counted positive toward the point). Map background shows the $0.5,1,2,3,4$ and $5 \mathrm{~km}$ isobaths of the GEBCO bathymetry. EGC=East Greenland Current, ENAC=Eastern North Atlantic Current, WNAC=Western North Atlantic Current, NIIC=North Irminger Icelandic Current, IC=Irminger Current. Adapted from Mercier et al. 2013 and Hansen and Østerhus 2000.

The heat content variations are linked to the ocean heat convergence and surface heat fluxes through the heat conservation equation:

$$
\frac{\partial h_{c}}{\partial t}=\iint_{S_{a}} Q_{n e t} d x d y+\rho_{0} C_{p} \oiiint_{S_{o}}[U T] d l d z+\varepsilon
$$

with $Q_{n e t}$ the net (latent, sensible, shortwave and longwave) surface heat fluxes, $S_{o}$ the outline surface of volume $V$ and $[U T]$ the ocean heat transport. The first term on the right-hand side of equation 2 represents the contribution of surface heat fluxes to changes in ocean heat content. In the following, a positive contribution implies that the ocean is warmed by the atmosphere (i.e. surface heat fluxes are, by convention, positive downward).

The second term represents the contribution of ocean heat convergence, which is the sum of the heat transports across all the sections that close the water volume $V$. For each model simulation, this contribution is computed using the "Physical Analysis of the Gridded Ocean" (PAGO) suite of programs, introduced in Deshayes et al. $(2014)^{3}$. It permits the inter-comparison of model outputs along predefined sections with

\footnotetext{
${ }^{3}$ See also http://www. whoi.edu/science/PO/pago/
} 
limited interpolation by connecting two section endpoints as a continuous sequence of grid faces following a great circle pathway. Current velocities along the section do not undergo any interpolation, while tracer fields are interpolated at the centre of the grid faces. In the low-resolution simulations (LR1, LR2 and LR3), monthly heat transports are computed by using PAGO on the monthly means of velocity and temperature. These monthly transports are then averaged over the winter months (December to March) or over the year (January to December). This methodology could not be applied to the HR model simulation because of computational constraints that prevented to use PAGO on its monthly outputs. Instead, PAGO was used on the winter and yearly averages of the $u T$ and $v T$ fields, with $u$ and $v$ the zonal and meridional current velocities and $T$ the temperature. We have verified that using this methodology with the LR runs does not change the values of the computed heat transports (not shown).

The $\varepsilon$ term is a residual that includes diffusive diapycnal mixing and numerical errors. To verify that it is negligible compared to the three other terms of equation 2, it has been computed following the methodology of Desbruyeres et al. (2014). Yearly means of ocean heat convergence and surface heat fluxes have been subtracted to the heat content variations between two consecutive January months. Table 2 shows, for each LR model simulation, the means and standard-deviations of the four terms in equation 2. Since the residual term shows a much smaller variance than ocean heat convergence and surface heat fluxes, its impacts on the heat content variability are minor. Consequently, it will be neglected in the following. Similar calculations were not performed for the HR simulation since, as discussed in the above, monthly transports were not available. Nonetheless, we assume that $\varepsilon$ is also negligible in this model simulation.

Table 2. Means and standard deviations of the terms in equation 2 (in $\mathrm{TW}=10^{12} \mathrm{~W}$ ).

\begin{tabular}{cccccc} 
Subregion & Simulations & $\partial h_{c} / \partial t$ & Ocean convergence & Surface fluxes & Residual \\
\hline \multirow{3}{*}{ West } & LR1 & $-1.05+/-40.54$ & $170.53+/-27.24$ & $-168.77+/-31.86$ & $-2.81+/-5.88$ \\
& LR2 & $1.05+/-39.93$ & $195.05+/-24.96$ & $-191.24+/-34.40$ & $-2.76+/-6.04$ \\
& LR3 & $-2.34+/-37.51$ & $170.15+/-25.23$ & $-173.15+/-33.67$ & $0.66+/-6.09$ \\
\hline \multirow{3}{*}{ East } & LR1 & $-0.36+/-23.86$ & $119.55+/-23.88$ & $-108.04+/-18.18$ & $-11.87+/-5.46$ \\
& LR2 & $1.95+/-25.16$ & $126.18+/-25.20$ & $-115.74+/-16.77$ & $-8.49+/-5.20$ \\
& LR3 & $-1.38+/-24.84$ & $107.75+/-23.88$ & $-103.69+/-16.22$ & $-5.44+/-5.06$ \\
\hline
\end{tabular}

3.3. Comparison with observational based estimates 3.3.1. Heat transports

At $46^{\circ} \mathrm{N}$, the LR models compare reasonably well with the observational-based (inverse model) estimates of Ganachaud and Wunsch (2003), as shown in table 3. The HR simulation, on the other hand, has a heat transport that is more than $200 \mathrm{TW}$ higher than observations, presumably due to the warm temperature 
bias in the North Atlantic Ocean (Molines et al. 2014). At $56^{\circ} \mathrm{N}$ and across the Greenland-Iceland-Scotland section, however, all models compare well with the observed estimates of Lumpkin and Speer (2007).

The Atlantic Water (AW in table 3) flowing across the IFO and FSO sections is defined following Aksenov et al. (2010) by salinity greater than 35 psu and potential temperature greater than $5^{\circ} \mathrm{C}$. Across the FSO section, the heat transport associated with the Atlantic Water compares well with observations in LR2 and HR but is overestimated in LR1 and LR3. In the LR simulations, the heat transport across the IFO section is underestimated by approximately $80 \mathrm{TW}$, while in the HR simulation it is underestimated by only 40 TW. This is presumably due to a too zonal North Atlantic Current in the LR simulations, a bias that is less visible in the HR one.

Table 3. Simulated and observed heat transports (in $\mathrm{TW}=10^{12} \mathrm{~W}$ ). Section names refer to figure 2. The period during which the transports are averaged is indicated in the second column.

\begin{tabular}{cccccccc} 
Section & Period & LR1 & LR2 & LR3 & HR & Observations & Reference \\
\hline \hline $46^{\circ} \mathrm{N}$ & 1993 & 648 & 673 & 617 & 853 & 600 & Ganachaud and Wunsch (2003) \\
$56^{\circ} \mathrm{N}$ & 1992 & 533 & 512 & 497 & 571 & 540 & Lumpkin and Speer (2007) \\
IFO+FSO+DSO & 1995 & 256 & 223 & 233 & 276 & 290 & Lumpkin and Speer (2007) \\
$\mathrm{AW}\left(S>35, \theta>5^{\circ} \mathrm{C}\right)$, FSO & $1999-2001$ & 173 & 156 & 189 & 156 & 156 & $\varnothing$ sterhus et al. (2005) \\
$\mathrm{AW}\left(S>35, \theta>5^{\circ} \mathrm{C}\right)$, IFO & $1999-2001$ & 61 & 57 & 61 & 92 & 134 & Østerhus et al. (2005)
\end{tabular}

\subsection{2. $0-700 \mathrm{~m}$ heat content anomalies}

Simulated and observed heat content in the top $700 \mathrm{~m}$ of the water column are compared in figure 3 . Observational-based (objective analysis) estimates are extracted from the EN3 (Ingleby and Huddleston 2007) and "World Ocean Atlas 2009" (WOA09, Locarnini et al. 2010) datasets.

In the western subpolar gyre, simulated heat content closely follows the WOA09/EN3 observations both in amplitude and in the timing of the fluctuations: the correlation between the EN3-WOA90 mean heat content (black curve in figure 3) and the simulated heat content is 0.94 for LR1 and LR2, 0.89 for LR3 and 0.86 for HR. The strong warming of 1995 is especially well captured by all simulations.

In the eastern subpolar gyre, simulated heat content anomalies are also consistent with observations, although correlations are slightly weaker than for the western subpolar gyre. The correlation between the EN3-WOA90 mean and the simulated heat content is 0.80 for LR1, 0.81 for LR2, 0.91 for LR3 and 0.7 for HR. The 1995 warming of the eastern subpolar gyre occurs at the same time as in the western subpolar gyre 

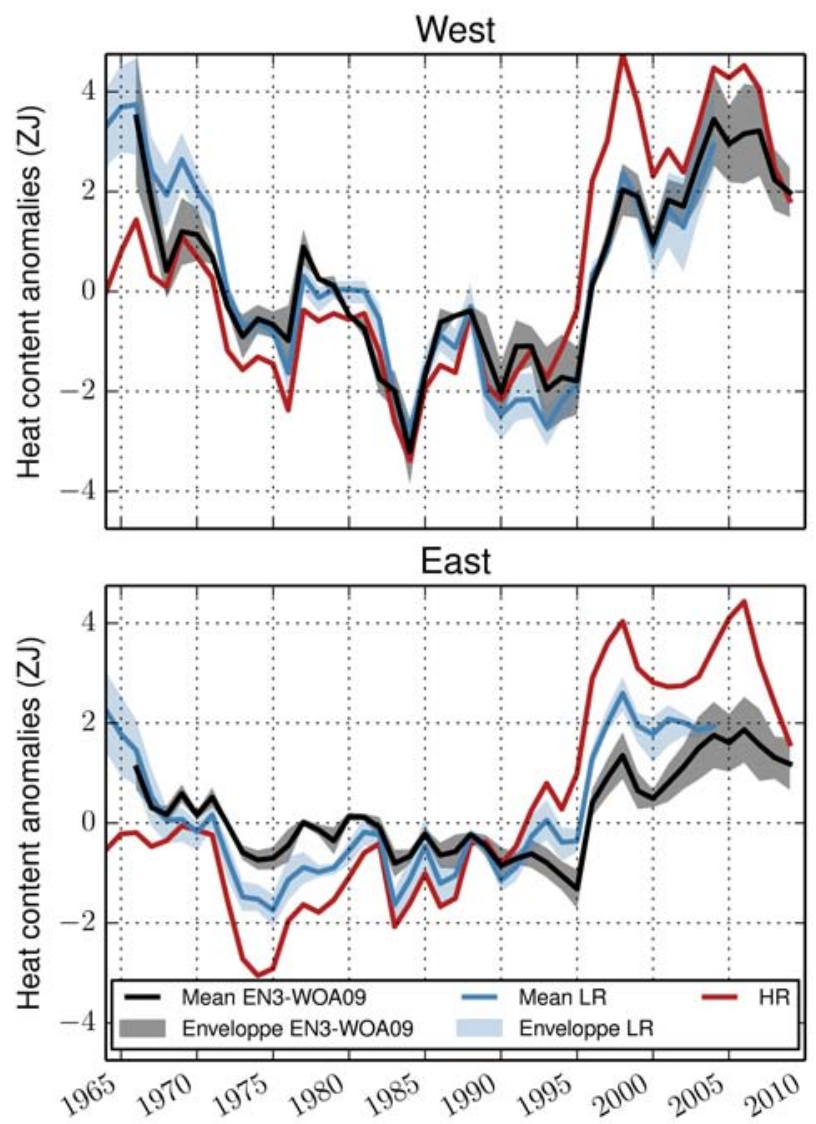

Figure 3. Yearly heat content anomalies (computed by removing the 1966-2006 mean, in ZJ=10 $21 \mathrm{~J}$ ) of the upper $700 \mathrm{~m}$ of the water column integrated over the western (upper panel) and eastern (lower panel) subpolar gyre in EN3-WOA09 observations (black line for the ensemble mean, gray shading for the enveloppe), LR simulations (blue line for the ensemble mean, blue shading for the enveloppe) and HR simulations (brown line).

and is also well captured by all simulations.

\section{Atmospheric weather regimes}

In order to determine how changes in the large-scale atmospheric circulation may have triggered the 1995 warming of the subpolar gyre, it is necessary to understand how they affect the variability of ocean heat convergence and surface heat fluxes, which are the two main contributors to the ocean heat content variability. In this study, the atmospheric variability is assessed using the so-called weather regimes as an alternative to the traditional climate indices. The weather regimes are large-scale, recurrent and quasi-stationary atmospheric patterns computed from daily winter sea-level pressure anomalies (computed by removing a smoothed seasonal cycle, for which two harmonics have been retained). The regimes are determined for the 1958-2010 period using the $k$-mean clustering algorithm of Michelangi et al. (1995), which relies on the 
recurrence property of the regimes. The aim of this method, a complete description of which is provided in Barrier et al. (2013), is to gather up days that share some ressemblance according to an Euclidian criteria. One limitation of the $k$-mean algorithm is the assumption that the number of regimes is a priori known. Michelangi et al. (1995) determined that the number of clusters that allows classificability and reproducibility is 4, which is the value determined using other methods (Vautard 1990). In the following, four winter weather regimes are thus considered.

Figure 4 (left panels) shows the weather regime composites of wind and air-temperature anomalies (computed by removing a smoothed seasonal cycle, for which two harmonics have been retained). These composites are computed by averaging the anomalies over all the winter days that belong to one specific regime. The "Atlantic Ridge" regime (AR hereafter) is associated with anticyclonic wind-anomalies centered in the subpolar gyre (figure 4a). The "Blocking" regime (BLK hereafter) is associated with northward wind anomalies in the eastern subpolar gyre, cooler temperature in the Labrador Sea and warmer temperature in the Nordic Seas (figure 4b). The $\mathrm{NAO}^{-}$regime, which is related to the negative phase of the NAO, is associated with reduced westerly winds and warm temperature anomalies in the Labrador Sea (figure 4c). The $\mathrm{NAO}^{+}$regime, which is related to the positive phase of the NAO, is associated with anomalies that are, to first order, opposite in sign to those associated with the $\mathrm{NAO}^{-}$(figure 4d).

The winter occurrences of the weather regimes, which we define as the number of days per winter that belong to each weather regime, depict strong interannual variability with abrupt year-to-year changes (figure 4, right panels, coloured histograms). For instance, between 1995 and 1996, the number of $\mathrm{NAO}^{+}$winter occurrences dropped by approximately 50 days. The time series also show decadal variability (black lines), especially for the two NAO-related regimes: before 1985, the atmospheric circulation is dominated by the $\mathrm{NAO}^{-}$regime and shows few $\mathrm{NAO}^{+}$days, and conversely after 1985.

Using the weather regime framework allows to get rid off orthogonality constraints and symmetry assumptions, which are peculiar to the traditional climate indices. The symmetry has been shown to be partially inadequate for the NAO, as discussed in Cassou et al. (2004). This is clearly visible in figure 4, where the wind anomalies associated with the $\mathrm{NAO}^{+}$regime are more zonally oriented than their $\mathrm{NAO}^{-}$ counterparts. This asymmetry has been shown to be particularly critical when assessing the NAO-driven variability of the gyre circulation. Using realistic and idealised model simulations, Barrier et al. (2014) have investigated the impacts of the weather regimes on the ocean circulation at interannual and decadal time scales. They suggest that the gyre response to persistent $\mathrm{NAO}^{+}$conditions is a strengthening of both gyres, while the gyre response to persistent $\mathrm{NAO}^{-}$is a cyclonic intergyre-gyre. Consequently, this asymmetry is expected to have an impact on the ocean heat convergence to the subpolar gyre. Furthermore, a winter 

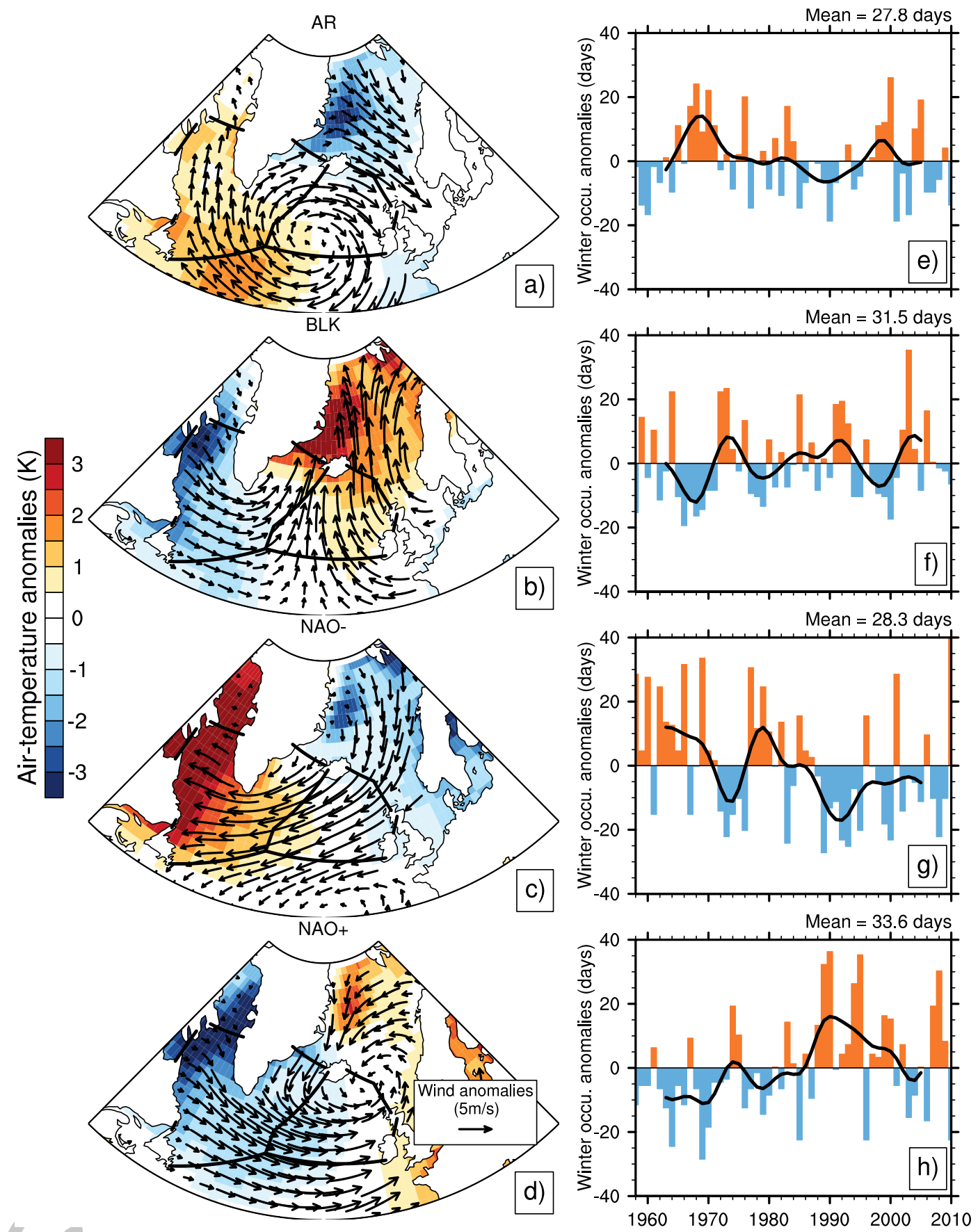

Figure 4. Composites of wind and air-temperature anomalies associated with each weather regime (left panels) and winter regime occurrence anomalies (right panels, in days, computed by removing the mean winter occurrences). Raw time series are shown in colors, while low-pass filtered time series (Lanczos filter, cut-off period of 10 years, 11 weights) are shown in black.

274 of strongly positive NAO index does not necessarily imply a lot of $\mathrm{NAO}^{+}$days. For instance, the 1992 275 winter is characterised by a NAO index of +1.80 but contains only $30 \%$ of days that belong to the $\mathrm{NAO}^{+}$ 
regime. The strongly positive winter NAO index of 1992 is in fact due to the very few $\mathrm{NAO}^{-}$days (only $4 \%$ ). Henceforth, we believe that the weather regimes better capture the true nature of the North Atlantic atmospheric variability.

\section{Impacts of the weather regimes on ocean heat convergence and surface heat fluxes}

In this section, the impacts of the weather regimes on the variability of ocean heat convergence and surface heat fluxes are assessed at interannual and decadal time scales.

\subsection{Interannual time scales}

During the winter season (December to March), the variance of surface forcings (wind and surface heat fluxes) is greater than in other seasons. Hence, changes in the large-scale atmospheric circulation are the most likely to impact the ocean circulation. Furthermore, Cassou et al. (2011) have shown that it is in winter that the relationships between the weather regimes and the surface forcings are the strongest. Therefore, to examine variability on interannual time scales, correlations between the winter-averaged ocean heat convergence/surface heat fluxes and the winter regime occurrences (figure 4, coloured histograms) are computed for each model simulation and for all the sections and subregions of figure 2. This winter averaging is expected to lay emphasis on the barotropic component of ocean heat convergence.

The significance of the correlations is assessed by a Student $t$-test. The number of degrees of freedom, $d f$, is given by:

$$
d f=(N-6)\left[\frac{1-a \times b}{1+a \times b}\right]
$$

with $N$ the number of observations, to which 6 is substracted since the time series are detrended and normalised prior to computing the correlations. The fraction term is a correction factor that takes into account the 1-lag autocorrelation of the two time series ( $a$ and $b$ in equation 3), as proposed by Bretherton et al. (1999, their equation 31). The correlations between the winter regime occurrences and the volume/heat transports on the one hand, and with surface heat fluxes/ocean heat convergence on the other hand, are shown in figures 5 and 6 , respectively. The correlations that are significant at the $95 \%$ level of confidence (bright colors in figures 5 and 6) for all simulations are summarised in figure 7 and discussed separately for each regime.

\subsubsection{Impacts of the "Atlantic Ridge" regime}

The negative correlations between the AR winter occurrences and the volume transport across SSE, SSW and MAR (figure 5) confirm that this regime is associated with a fast, wind-driven barotropic weakening 
Correlations with volume transports
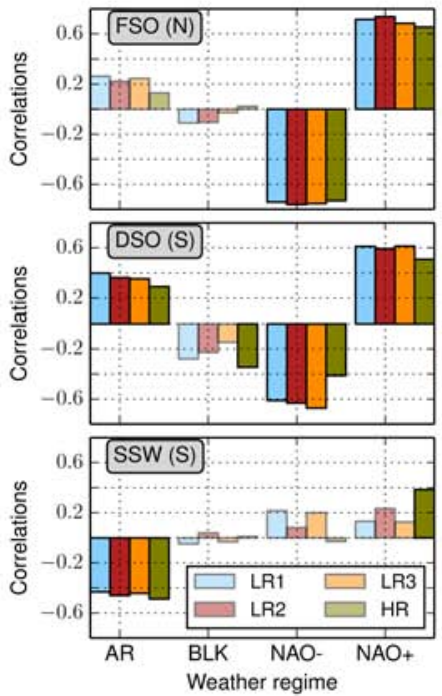
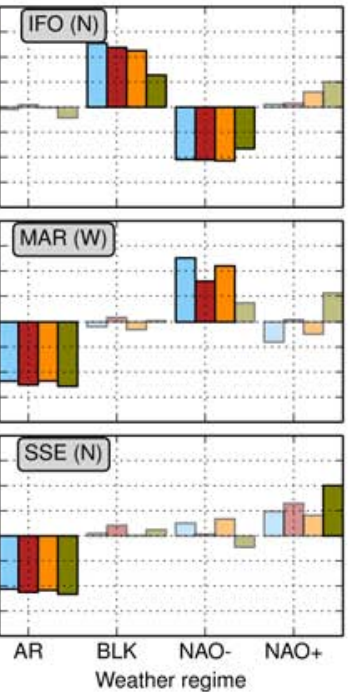

Correlations with heat transports
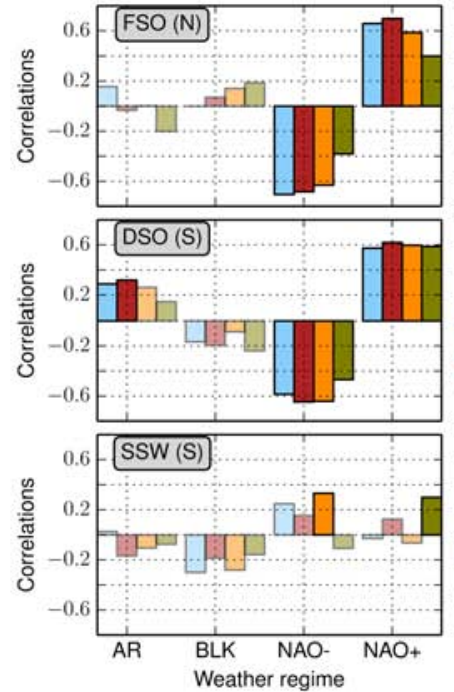
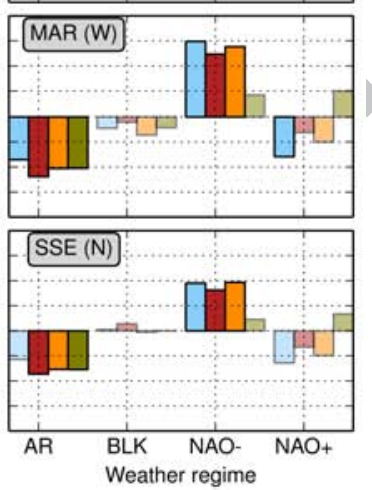

Figure 5. Correlations between the winter regime occurrences and the winter averaged volume (left panels) and heat (right panels) transports across the individual sections of figure 2. The names of the sections are provided in the upper left corner. Each color represents one model simulation. The direction in which the transports are defined positive is indicated in parenthesis. Significant correlations (Student's $t$-test at the $95 \%$ level of confidence, see text for details) are shown in bright colors.
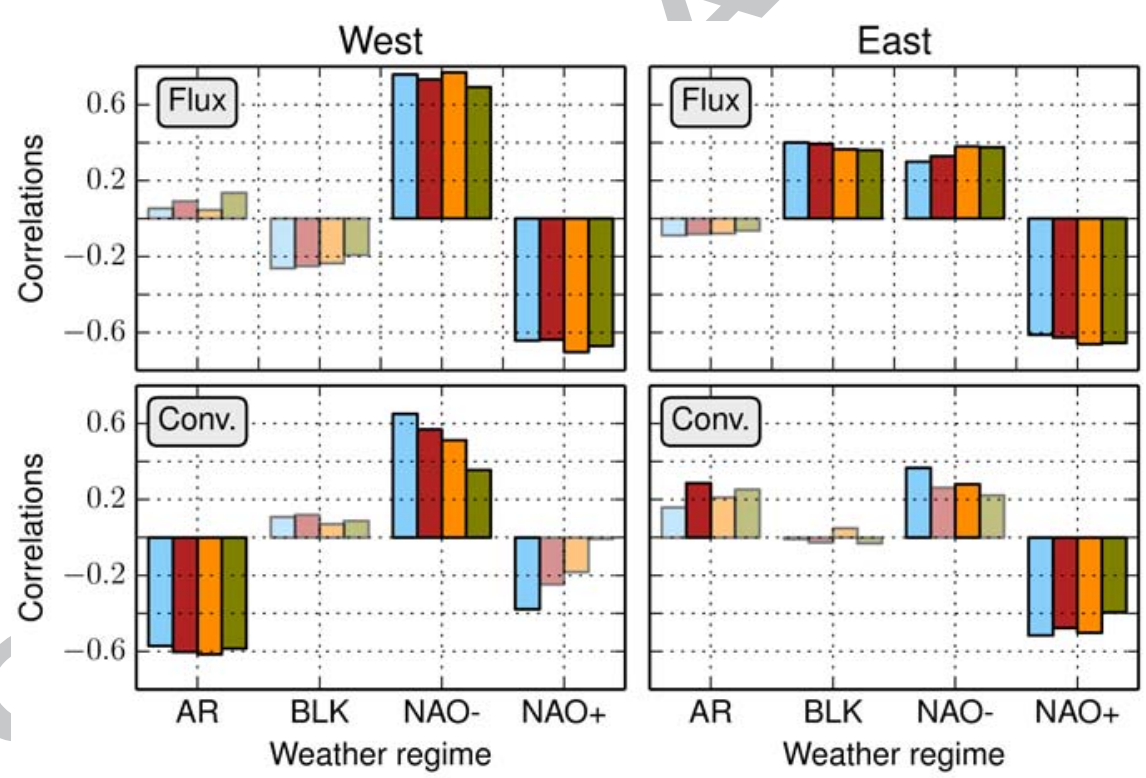

Figure 6. Correlations between the winter regime occurrences and the winter averaged surface heat fluxes (upper panels) and ocean heat convergence (lower panels) in the western (left panels) and eastern (right panels) subpolar gyre. Each color represents one model simulation. Significant correlations (Student's $t$-test at the $95 \%$ level of confidence, see text for details) are shown in bright colors. 
of the gyre circulation, as already proposed by Häkkinen et al. (2011a), Langehaug et al. (2012), RuprichRobert and Cassou (2013), Barrier et al. (2013) and Barrier et al. (2014). However, this weakening is not associated with an increased heat convergence in the subpolar gyre, as suggested by Häkkinen et al. (2011a). On the contrary, ocean heat convergence in the western subpolar gyre is reduced under AR conditions for each model simulation (figure 6). This is mostly due to the reduced heat transport across MAR that results from the reduced volume transport. The correlations between the AR winter occurrences and the surface heat fluxes in both subpolar regions are not significant. This is consistent with Barrier et al. (2014), who suggest that the impacts of the AR regime on the ocean circulation are mostly wind-driven.

\subsubsection{Impacts of the "Scandinavian Blocking" regime}

Correlations in figure 5 suggest that the BLK regime is associated with increased northward volume and heat transports across IFO. This is consistent with Nilsen et al. (2003) and, to some extent, Medhaug et al. (2012). The latter study suggests that the wind anomalies associated with the BLK regime have both a direct and an indirect impact on the heat transport across the Greenland-Scotland Ridge. The direct effect is induced by eastward Ekman transport anomalies that induce along-ridge gradients of sea-surface height and in turn a northward geostrophic flow. The indirect effect is due to a barotropic adjustment of the Nordic Seas, leading to a weaker Norwegian Atlantic Current and consequently to a weaker northward heat transport. The correlations shown in figure 5 are consistent with the direct effect discussed by Medhaug et al. (2012). This is not surprising since both the winter averaging and the in-phase correlations ultimately amplify the fast, direct influence of winds on volume and heat transports. The BLK regime is also associated with reduced surface heat loss in the eastern subpolar gyre (figure 6), but the correlations are weak (less than 0.4, albeit significant).

\subsubsection{Impacts of the $\mathrm{NAO}^{-}$regime}

In all $\mathrm{LR}$ simulations, $\mathrm{NAO}^{-}$conditions are associated with increased westward volume and heat transports across MAR and in turn to increased heat convergence in the western subpolar gyre (figure 6). This is the signature of a cyclonic intergyre-gyre driven by the wind-anomalies through topographic Sverdrup balance, as discussed in Marshall et al. (2001), Eden and Willebrand (2001), Herbaut and Houssais (2009) and Barrier et al. (2014). Note that the correlations between the transports across MARand the NAO ${ }^{-}$ winter occurrences are weak and therefore not significant in the HR simulation. This is due to strong negative anomalies of volume and heat transports that occurred in 1996 in this simulation, which did not occur in the LR simulations (not shown). If this year is removed prior to computing the correlations between the transports across MAR and the $\mathrm{NAO}^{-}$occurrences, these correlations become significant in $\mathrm{HR}$. The 
increased volume and heat transports across MAR is associated with increased northward volume and heat transports across DSO by the North Icelandic Irminger Current. The $\mathrm{NAO}^{-}$regime is also associated with southward volume and heat transport anomalies across IFO and FSO. These anomalies are in the same direction as the wind anomalies in this region; hence, as for the BLK regime, they are presumably due to the direct, Ekman-driven impact of wind-anomalies on the transports, as described in Medhaug et al. (2012). The $\mathrm{NAO}^{-}$regime is also associated with reduced heat loss in the western and eastern subpolar gyres (correlations of 0.6 and 0.3 , respectively, figure 6 ).

\subsubsection{Impacts of the $\mathrm{NAO}^{+}$regime}

The $\mathrm{NAO}^{+}$regime is associated with decreased ocean heat convergence in the eastern subpolar gyre (figure 6), primarily due to northward volume and heat transport anomalies across FSO, consistently with Mauritzen et al. (2006) and Frankignoul et al. (2009). These transport anomalies are again in the same direction as the wind anomalies associated with the $\mathrm{NAO}^{+}$and are thus consistent with the Ekman-driven mechanism discussed for the $\mathrm{BLK}$ and $\mathrm{NAO}^{-}$regimes. The $\mathrm{NAO}^{+}$regime also induces southward volume and heat transport anomalies across DSO. These anomalies are due to both a strengthening of the southward East Greenland Current and a weakening of the northward North Icelandic Irminger Current. The $\mathrm{NAO}^{+}$regime is also associated with a strong increase in surface heat loss in the two subpolar subregions (correlations of -0.6 in both regions). The strong heat loss in the eastern subpolar gyre is consistent with the eastward extension of the negative air-temperature anomalies associated with the $\mathrm{NAO}^{+}$regime (figure 4 ), which tend to extract heat from the ocean. Note that the correlations between the $\mathrm{NAO}^{-} / \mathrm{NAO}^{+}$occurrences and the volume/heat transports, summarised in figure 7, are not strictly opposite to one another. This emphasizes the importance of the NAO asymmetry when considering the interannual variability of the barotropic component of ocean volume and heat tranports, and therefore the use of the weather regime framework. 

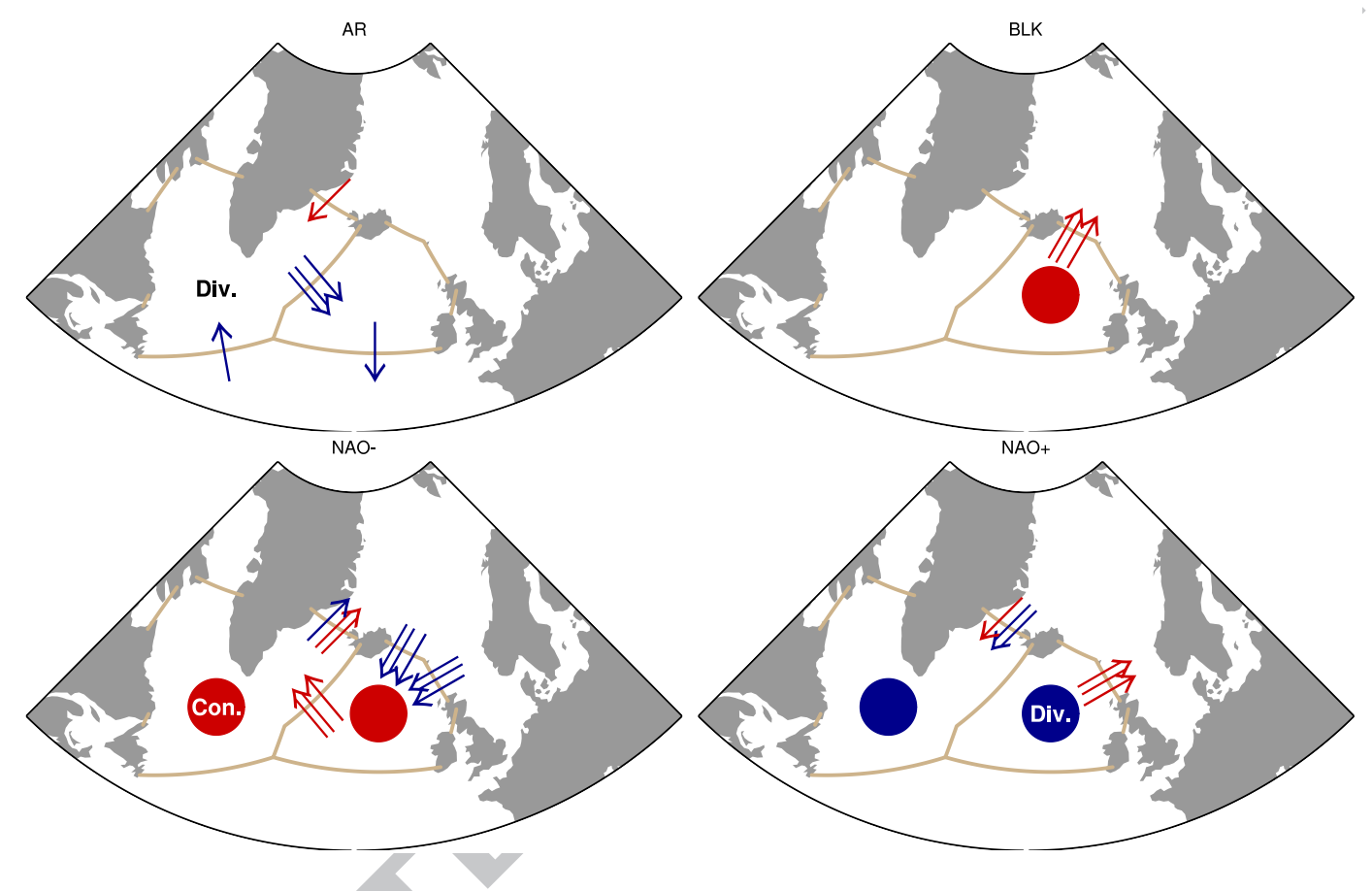

Figure 7. Correlations between the winter regime occurrences and surface heat fluxes (filled circles, positive correlations in red, negative correlations in blue), volume (single arrows) and heat transports (double arrows). Only the correlations that are significant at the $95 \%$ level of confidence for all model simulations are shown. The red arrows indicate that the correlation is of the same sign as the mean (i.e. that the transport is reinforced), conversely for the blue arrows. "Div." indicates a divergence of heat out of the subregion, while "Con." indicates a convergence of heat into the subregion. 


\subsection{Decadal time scales}

The impacts of the weather regimes on ocean heat convergence and surface heat fluxes in each region are now investigated on decadal time scales. This is achieved by computing the lagged cross-correlations between the low-pass filtered winter regime occurrences (figure 4, black lines) and the low-pass filtered yearly averaged ocean heat convergence/surface heat fluxes. All time-series have been detrended prior to filtering and to computing the correlations. The filter that has been used is a Lanczos filter with a cut-off period of 10 years and 11 weights. Because of the strong autocorrelation of the time-series and the small number of years, the number of degrees of freedom is weak and the significance of the correlations cannot be determined as done in the previous section. As an alternative, correlations are considered as robust when they are similar among all model simulations, an admittedly subjective methodology.

\subsubsection{Western subpolar gyre}

Ocean heat convergence and surface heat fluxes in the western subpolar gyre show the strongest correlations with $\mathrm{NAO}^{-}$and $\mathrm{NAO}^{+}$winter occurrences. Surface heat fluxes are positively correlated with $\mathrm{NAO}^{-}$ winter occurrences at 0-lag (figure 8b), while ocean heat convergence is negatively correlated with a lag of approximately 2-3 years ( $\mathrm{NAO}^{-}$occurrences leading). Therefore, $\mathrm{NAO}^{-}$conditions are associated with reduced surface heat loss in the western subpolar gyre. After 2-years, this heat gained by the ocean is compensated for by reduced ocean heat convergence. This is further confirmed by the lagged correlations between low-pass filtered surface heat fluxes and ocean heat convergence in the western subpolar gyre, which suggest that surface heat fluxes drive ocean heat convergence with a lag of 2 to 4 years (not shown).

The negative correlations between $\mathrm{NAO}^{-}$occurrences and ocean heat convergence in the western subpolar gyre are due to the baroclinic spin-down of the meridional overturning circulation, as discussed in Barrier et al. (2014). Reduced ocean heat loss through surface heat fluxes reduces deep convection in the Labrador Sea, which in turn induces a large-scale weakening of the meridional overturning circulation (Deshayes and Frankignoul 2008). As a consequence, the poleward heat transport is reduced, inducing a divergence of heat out of the western subpolar gyre, as discussed for instance in decadal prediction experiments (Yeager et al. 2012, Robson et al. 2012, Msadek et al. 2014) and in Lohmann et al. (2009).

Note that contrary to the correlations at interannual time scales, the correlations depicted in figure 8 for the $\mathrm{NAO}^{+}$regime mirror those for $\mathrm{NAO}^{-}$, which suggests that the $\mathrm{NAO}^{+}$regime is associated with increased surface heat loss that is balanced with an increased heat convergence associated with a largescale strengthening of the meridional overturning circulation. This is expected from Barrier et al. (2014) who suggest that the response of the meridional overturning circulation to persistent $\mathrm{NAO}^{-}$and $\mathrm{NAO}^{+}$ 


\section{ACCEPTED MANUSCRIPT}

Barrier et al. / Progress in Oceanography 00 (2014) 1-35
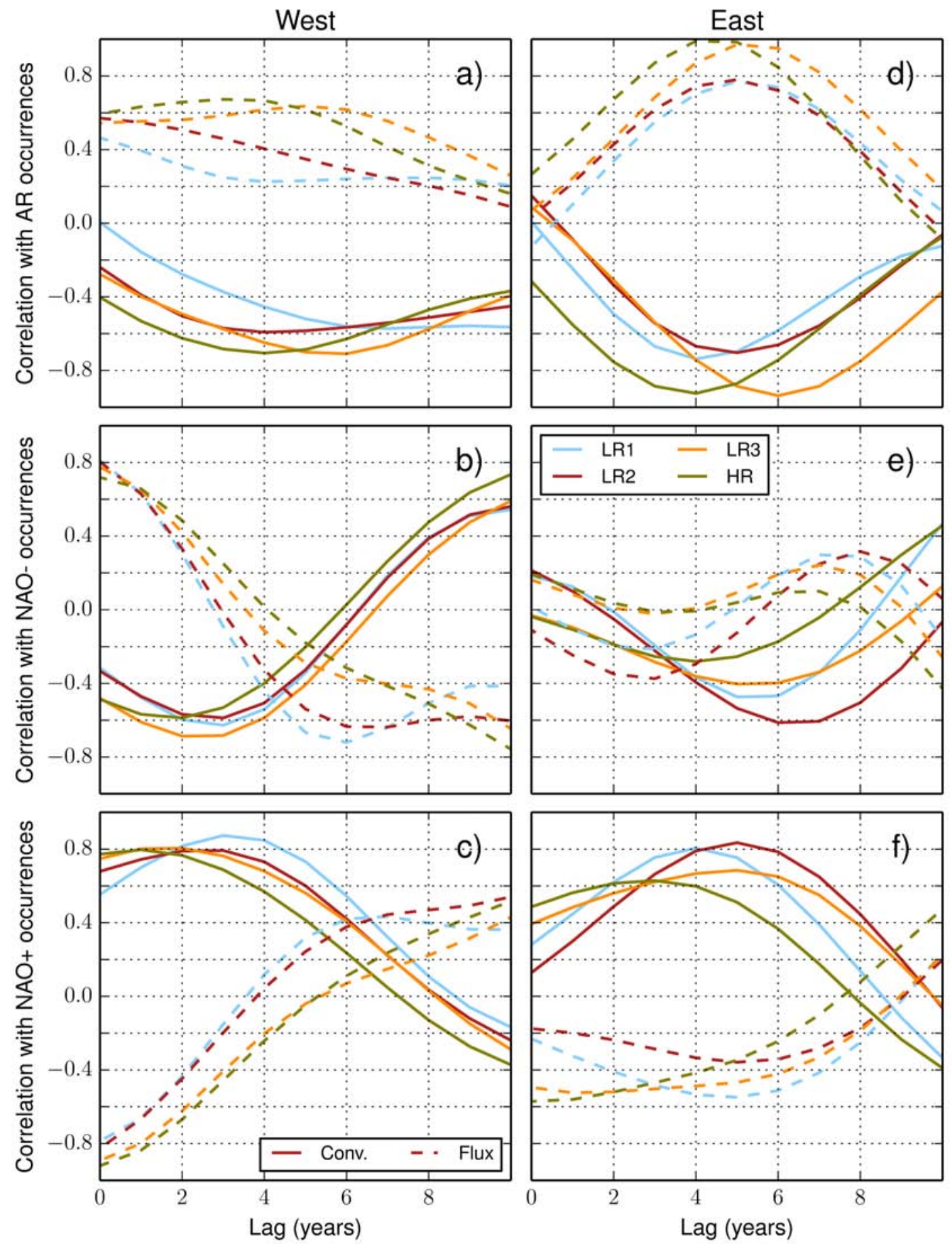

Figure 8. Correlations between the low-pass filtered winter regime occurrences and the low pass filtered ocean heat convergence (solid lines) and surface heat fluxes (dashed lines) in the western (left panels) and eastern (right panels) subpolar gyre. The regime occurrences lead. The time series have been filtered with a Lanczos filter of 11 weights and a cut-off period of 10 years. Each color represents one model simulation. 
atmospheric conditions are opposite to each other.

\subsubsection{Eastern subpolar gyre}

In the eastern subpolar gyre, the correlations between ocean heat convergence and winter regime occurrences are less clear than in the western subpolar gyre. In this region, heat convergence increases 3 to 6 years after $\mathrm{NAO}^{+}$conditions and decreases 3 to 6 years after AR conditions. At these time scales, the dominant response of the ocean circulation to the AR regime is a wind-driven reduction of both subpolar and subtropical gyres, with a limited reduction of the meridional overturning circulation (Barrier et al. 2014). On the other hand, the decadal ocean response to the $\mathrm{NAO}^{+}$regime is a wind-driven strengthening of the subtropical gyre and a buoyancy-driven strengthening of the subpolar gyre and of the meridional overturning circulation (Barrier et al. 2014). Since these two regimes have a different impact on the meridional overturning circulation, only the anomalous gyre circulation can explain the similarity of the correlations between the $\mathrm{AR}$ and $\mathrm{NAO}^{+}$occurrences on the one hand, and the ocean heat convergence in the eastern subpolar gyre on the other hand. As a consequence, we suggest that during $\mathrm{NAO}^{+}$conditions, the strengthening of the subtropical gyre leads to an increased heat transport by the North Atlantic Current, mainly through increased heat transport across the SSE section, with a reduced positive contribution by the meridional overturning circulation. Conversely, the AR regime would induce a weakening of the subtropical gyre and, as a consequence, a decrease in heat transport by the North Atlantic Current.

The correlations between the $\mathrm{NAO}^{-}$occurrences and ocean heat convergence in the eastern subpolar gyre are weaker than for the AR and $\mathrm{NAO}^{+}$regimes. As shown in Barrier et al. (2014), the baroclinic response of the gyre circulation to persistent $\mathrm{NAO}^{-}$conditions is a cyclonic intergyre-gyre centred at $45^{\circ} \mathrm{N}$. Its southern branch would be associated with increased heat transport into the eastern subpolar gyre by the North Atlantic Current, while its northern branch would advect warm water from the eastern subpolar gyre to Newfoundland. As a consequence, both contributions compensate each other and the decadal variability of the $\mathrm{NAO}^{-}$regime has a limited impact on the decadal variability of ocean heat convergence in the eastern subpolar gyre. Using the traditional NAO index, Herbaut and Houssais (2009) suggest that positive NAO conditions are associated with an anticyclonic intergyre-gyre. Its southern branch would be associated with reduced heat transport by the North Atlantic Current, while its northern branch would advect cold water from Newfoundland to the eastern subpolar gyre. Hence, its two branches would contribute to cooling the eastern subpolar gyre. However, taking into account the NAO spatial asymmetry suggests that the gyre response to persistent $\mathrm{NAO}^{+}$conditions is not an anticyclonic intergyre-gyre (Barrier et al. 2014). Therefore, the mechanism of Herbaut and Houssais (2009) may not hold here. This highlights the importance of considering the NAO asymmetry and further motivates using the weather regimes instead of the traditional climate indices. 
The correlations between the $\mathrm{AR}$ and $\mathrm{NAO}^{-}$occurrences on the one hand and surface heat fluxes on the other hand mirror, to some extent, the correlations with ocean heat convergence. This likely reflects the ocean influence on the surface heat flux at these time scales in this region, as proposed by Grist et al. (2010) and Desbruyeres et al. (2014). For these two regimes, the air-temperature anomalies are very small over the eastern subpolar gyre (figure 4). As a consequence, surface heat fluxes at these time scales are dominated by changes in ocean sea-surface temperature rather than by changes in surface air-temperature. Hence, when ocean heat convergence increases, the ocean becomes warmer and ultimately warms the atmosphere, as suggested in figures $8 \mathrm{~d}$ and $8 \mathrm{e}$. This is partly confirmed by the lead-lag correlations between the lowpass filtered heat convergence and surface heat flux in the eastern subpolar gyre, which shows a maximum correlation when convergence leads by 0 to 2 years, except for the LR3 simulation, in which the correlation is maximum when the surface fluxes lead by 1 year. For the $\mathrm{NAO}^{+}$regime, the correlations with surface heat fluxes are unclear, which we fail to explain. It may reflect the negative influence of a reduced stratification on the ocean feedback on surface heat fluxes.

\section{Heat content anomalies and the warming event of 1995}

This section is devoted to understand the causes of the 1995 warming event by assessing the respective contributions of ocean heat convergence and surface heat fluxes on the ocean heat content. This is achieved by integrating equation 2 over time, assuming that the residual $\epsilon$ is neglibible (as justified in section 3):

$$
\int_{t_{0}}^{t} \frac{\partial h_{c}}{\partial t}=h_{c}(t)-h_{c}\left(t_{0}\right)=\int_{t_{0}}^{t}\left[\iint_{S_{a}} Q_{n e t} d x d y\right] d \lambda+\int_{t_{0}}^{t}\left[\rho_{0} C_{p} \int_{S_{o}}\left[U T_{i n t}\right] d l d z\right] d \lambda
$$

Using the results of the previous section, the 1995 warming event is then related to changes in the large-scale atmospheric circulation using the weather regime framework.

\subsection{Western subpolar gyre}

In the western subpolar gyre, heat content anomalies show similar behaviour among all model simulations (figure 9a). Still, differences are visible when surface heat fluxes and ocean heat convergence are taken separately (figures $9 \mathrm{~b}$ and $9 \mathrm{c}$ ). While the time series of both components are very similar among LR simulations, they show larger amplitudes in HR (15 ZJ against 5 ZJ for the maximum of all LR simulations) because of linear trends in ocean heat convergence and surface heat fluxes that compensate each other.

Between 1992 and 2000, ocean heat convergence shows large positive anomalies (figure 10, blue curve) that are balanced by strong surface heat loss prior to 1992 (negative anomalies, red line in figure 10). However, between 1992 and 1994, this surface heat loss weakens and is ultimately dominated by ocean heat 
convergence. Consequently, the net heat input anomalies become positive from 1994 to 1998, which explains the 1995 warming event of the western subpolar gyre.

The strong ocean heat convergence in the western subpolar gyre between 1992 and 2000 is due to the buoyancy-driven spin-up of the meridional overturning circulation following the $\mathrm{NAO}^{+}$conditions of 19881995. Indeed, as shown in figure 8, a decadal increase in the $\mathrm{NAO}^{+}$winter occurrences is associated with an in-phase increase in surface ocean heat loss, as evidenced in figures $9 \mathrm{~b}$ and 10 . This causes anomalously strong deep convection in the western subpolar gyre, as observed by Yashayaev (2007), and in turn induces a lagged (2-3 years) increase in ocean heat convergence via a large-scale strengthening of the meridional overturning circulation. When the decadal $\mathrm{NAO}^{+}$episode stops, surface ocean heat loss is reduced, as evidenced here, but the meridional overturning circulation and the associated ocean heat convergence remain strong for at least 2-3 years, hence ultimately dominating the ocean heat loss.

This is consistent with the description of heat content variability in the Labrador Sea provided by Lazier et al. (2002) for the period 1992-2000 and with the decadal prediction experiments of Robson et al. (2012), Yeager et al. (2012) and Msadek et al. (2014), who suggest that the warming of the subpolar gyre can be predicted only if the ocean is initialised with a strong meridional overturning circulation resulting from the 1988-1995 $\mathrm{NAO}^{+}$conditions.

\subsection{Eastern subpolar gyre}

In the eastern subpolar gyre, all simulations show strikingly similar fluctuations in all 3 terms (figure 11). The amplitude of heat content anomalies is much weaker than the amplitude of its two components (ocean heat convergence and surface heat flux). Indeed, since decadal changes in ocean heat convergence drive opposite changes in surface heat fluxes, as discussed in section 5.2, these two components tend to cancel each other.

In the eastern subpolar gyre, the warming event of 1995 seems mostly due to a sharp increase in ocean heat convergence during this year (figure 12, blue curve). Afterward, ocean heat convergence either remains steady (in LR1 and LR2) or decreases (in LR3 and HR). At the same time, surface heat loss is reduced, hence sustaining the positive net heat input anomalies until 1997 and ultimately leading to an increase in ocean heat content. The 1995 increase in ocean heat convergence is mainly due to the increased heat convergence that occurred in November and December, when the atmospheric circulation is dominated by the $\mathrm{NAO}^{-}$regime (figure 13), and is dominated by the increased northward heat transport across the SSE section (figure 14). This is consistent with the correlations shown in figure 6 (although the correlation is not significant in the HR simulation) and reflects the wind-driven cyclonic intergyre-gyre that is triggered 


\section{ACCEPTED MANUSCRIPT}

Barrier et al. / Progress in Oceanography 00 (2014) 1-35
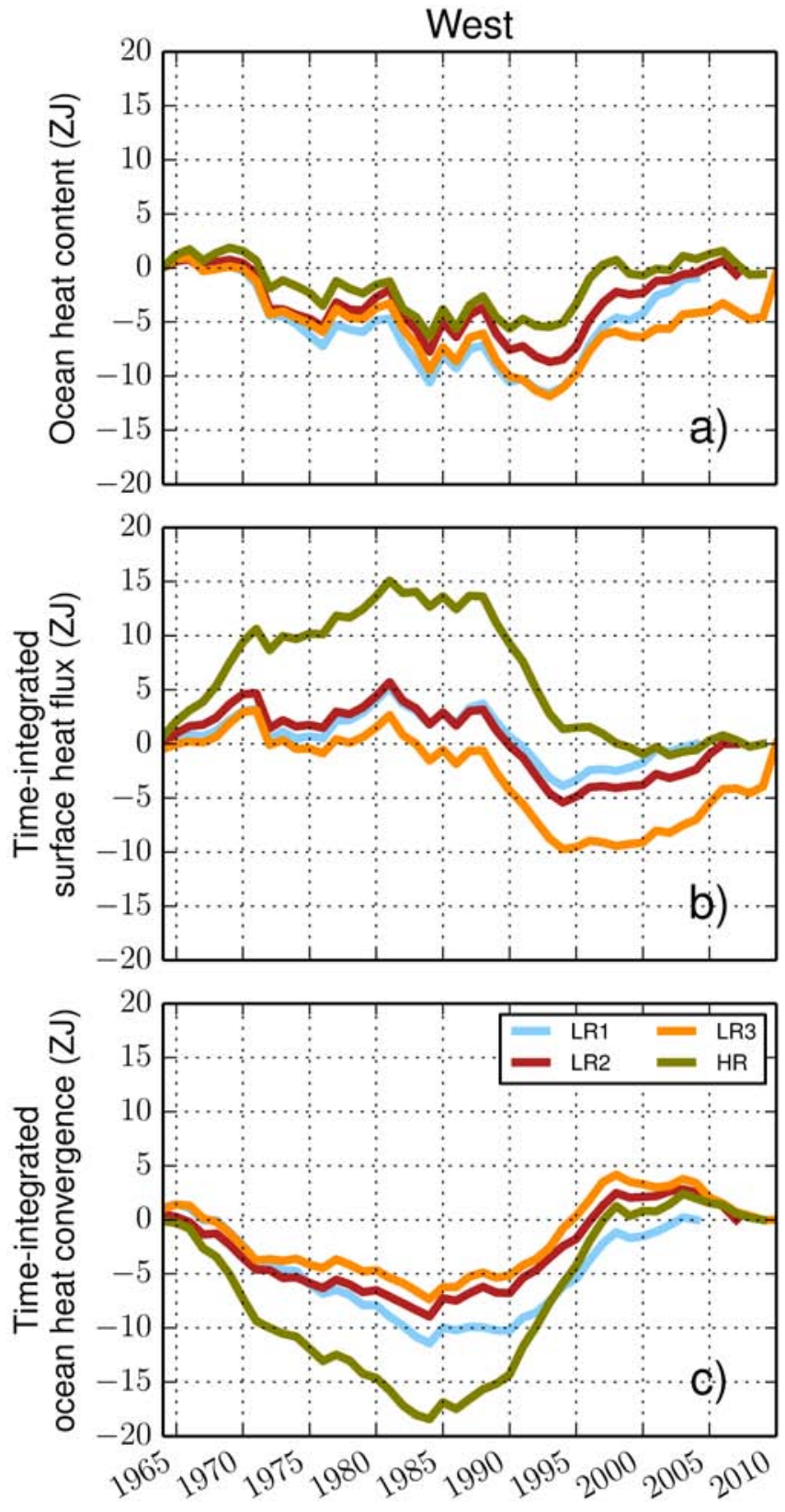

Figure 9. Ocean heat content (top), time-integrated surface heat fluxes (middle) and time-integrated ocean heat convergence (bottom) in the western subpolar gyre (cf. equation 4). Each color represents a model simulation.

when the atmosphere switches from $\mathrm{NAO}^{+}$to $\mathrm{NAO}^{-}$conditions.

\section{Conclusion and discussions}

This study aimed at understanding the causes of the unprecedented warming of the North Atlantic subpolar gyre that occurred in 1995. This warming event has been thoroughly studied in the literature, 


\section{West}
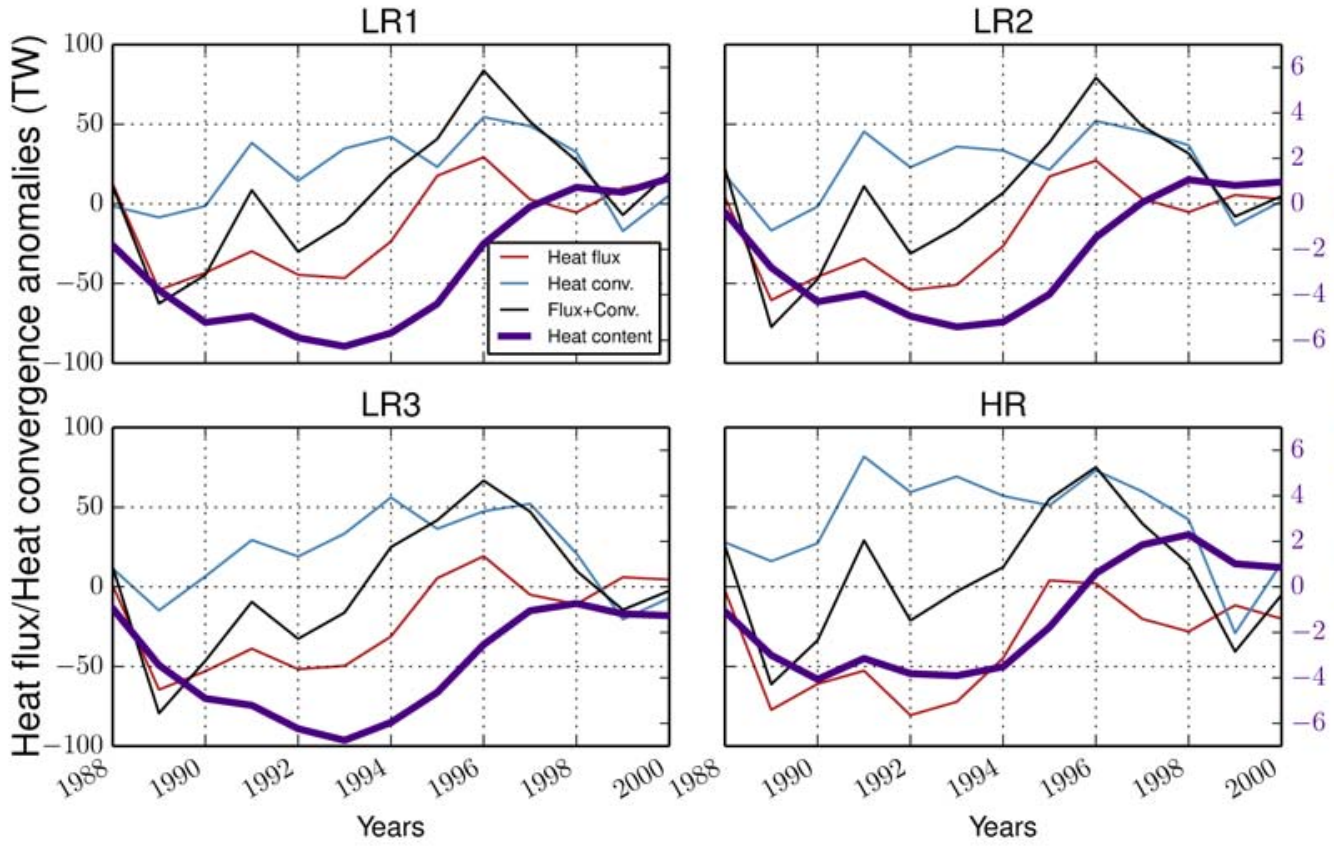

HR

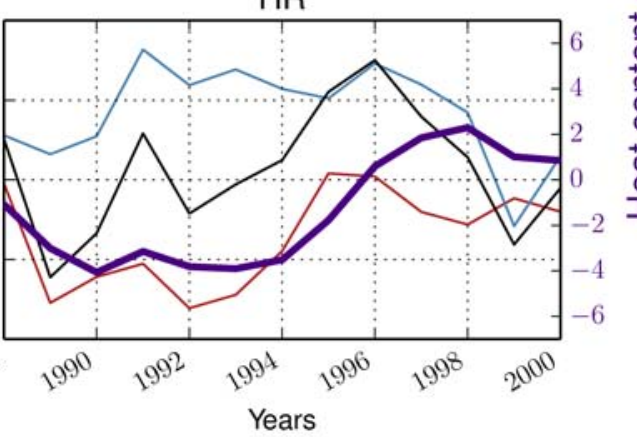

Figure 10. Anomalies of surface heat fluxes (red lines, in TW), ocean heat convergence (blue lines, in TW), net heat input (sum of the two contributions, black lines in TW) and ocean heat content (indigo lines, in ZJ) in the western subpolar gyre and in each model simulation. The anomalies are computed by removing the yearly means.

and despite the general agreement about the atmospheric triggering of this warming, strong uncertainties remain concerning the large scale atmospheric pattern (North Atlantic Oscillation or East Atlantic Pattern), the time scales (interannual or decadal) and the physical mechanisms involved. In order to address these questions, heat budget calculations are performed in the subpolar North Atlantic using four global ocean hindcasts sharing the same modelling framework but using different atmospheric forcings, resolutions and parameterisations. A novelty of the present work is the further decomposition of the subpolar gyre into a western and an eastern subregion that are separated by the Reykjanes and Mid-Atlantic Ridges. Such decomposition is presently unique and is consistent with the water masses distribution around the Reykjanes Ridge, as discussed by Thierry et al. (2008).

In the two subregions, ocean heat convergence and surface heat fluxes, which are the two main contributors to ocean heat content variability, are linked to changes in the atmospheric circulation at interannual and decadal time scales. Another novelty of the present work is the use of the weather regimes to describe the large-scale atmospheric variability, instead of using the traditional climate indices such as the North Atlantic Oscillation (NAO). This choice is motivated by the NAO spatial asymmetry (Cassou et al. 2004), which is paramount when investigating the NAO-driven variability of the gyre circulation (Barrier et al. 

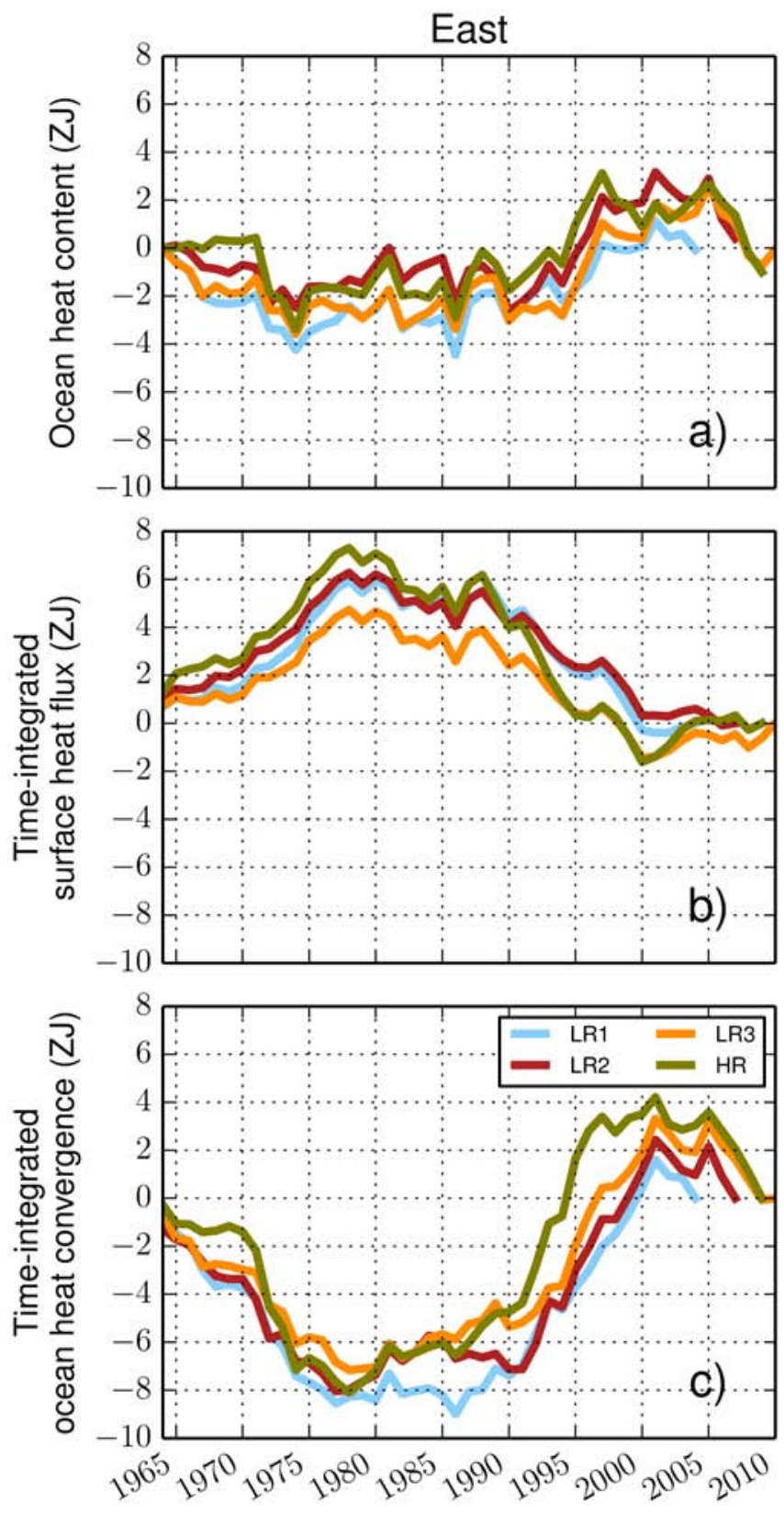

Figure 11. Ocean heat content (top), time-integrated surface heat fluxes (middle) and time-integrated ocean heat convergence (bottom) in the eastern subpolar gyre (cf. equation 4). Each color represents a model simulation.

2014).

As a first step, the relationships between the winter average (December to March) surface heat fluxes/ocean heat convergence and atmospheric weather regimes are determined using correlation analysis. At these time scales, the heat exchange between the eastern and western subpolar regions are governed by the Sverdrupian 


\section{East}
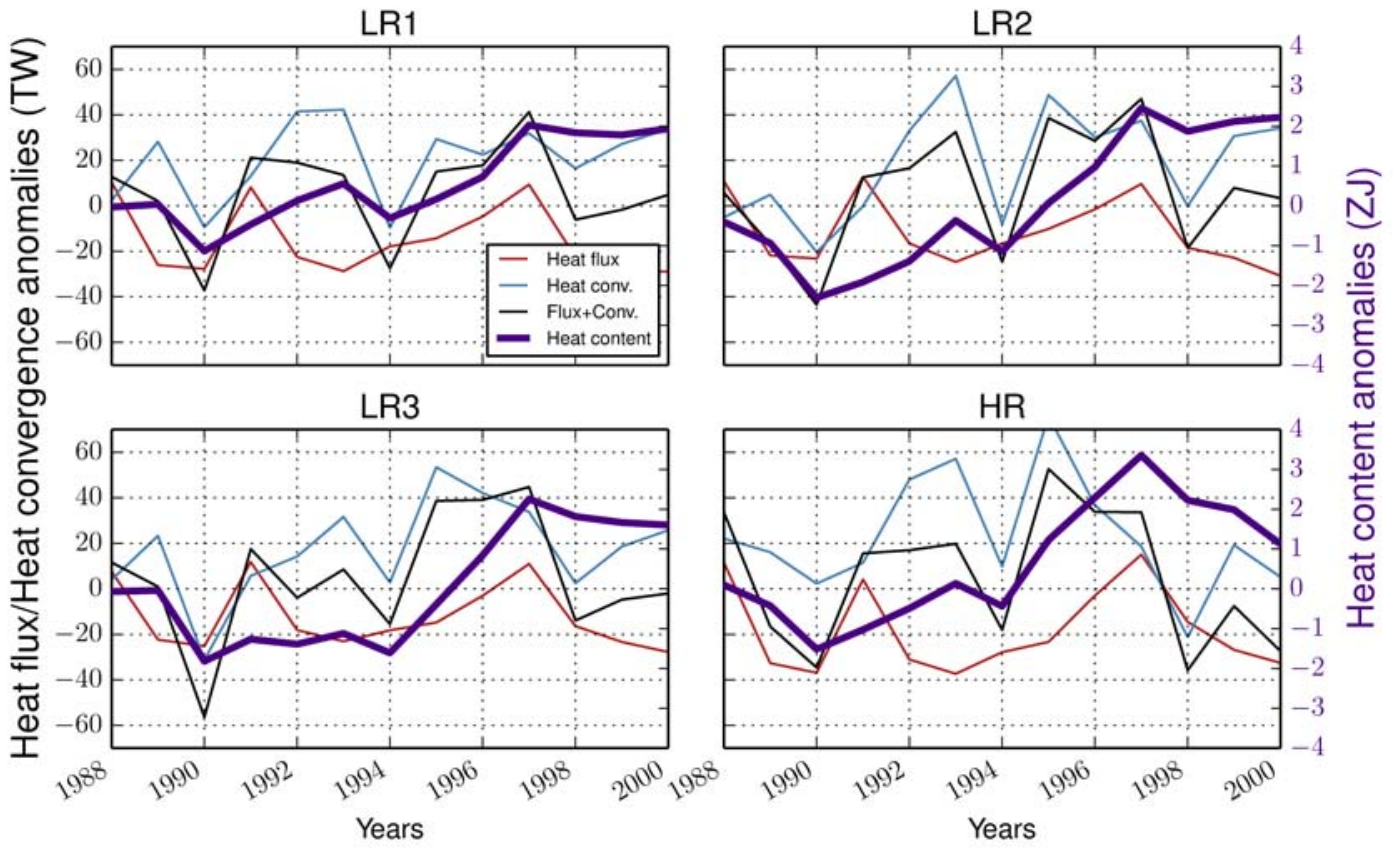

Figure 12. Anomalies of surface heat fluxes (red lines, in TW), ocean heat convergence (blue lines, in TW), net heat input (sum of the two contributions, black lines in TW) and ocean heat content (indigo lines, in ZJ) in the eastern subpolar gyre and in each model simulation. The anomalies are computed by removing the yearly means.

gyre response to the wind anomalies associated with the weather regimes (Barrier et al. 2014), while the heat transports across the Iceland-Faroe and Faroe-Scotland sills are driven by Ekman-induced geostrophic flows, which are in the same direction as the wind-anomalies, consistent with the "direct effet" described in Medhaug et al. (2012). The interannual variability of surface heat fluxes is dominated by the two NAOrelated weather regimes, consistently with the strong air-temperature anomalies in the subpolar gyre that are associated with these two regimes.

As a second step, the links between the weather regimes and ocean heat convergence and surface heat fluxes are analysed on decadal time scales. In the western subpolar gyre, the variability of surface heat fluxes is dominated by the NAO-related regimes, with ocean heat convergence playing a compensating role via the meridional overturning circulation. In the eastern subpolar gyre, ocean heat convergence is dominated by the baroclinic adjustment of the gyre circulation and shows an increase following $\mathrm{NAO}^{+}$conditions and a decrease following AR conditions. The impacts of the $\mathrm{NAO}^{-}$regime are weaker, since the northern and southern branches of the wind-driven cyclonic intergyre-gyre associated with the $\mathrm{NAO}^{-}$regime compensate each other. 
These results are then used to interpret the 1995 warming event in the two subpolar subregions. In the western subregion, the warming is due to the strong $\mathrm{NAO}^{+}$conditions that occurred during 1988-1995, which have induced large heat loss through surface heat fluxes. This has induced anomalously strong convection (Yashayaev 2007) and in turn a stronger meridional overturning circulation and ocean heat convergence in this subregion. The contributions of surface heat fluxes and ocean heat convergence balance each other until 1992, when surface ocean heat loss is reduced and finally dominated by ocean heat convergence in 1995, hence leading to the warming. This is consistent with the description of heat content variability in the Labrador Sea provided by Lazier et al. (2002) for the period 1992-2000 and with the decadal prediction experiments of Robson et al. (2012), Yeager et al. (2012) and Msadek et al. (2014). In the eastern subpolar gyre, the warming originates from an abrupt change in the ocean heat convergence, which is due to an abrupt switch from $\mathrm{NAO}^{+}$to $\mathrm{NAO}^{-}$conditions between 1995 and 1996. The wind anomalies associated with the $\mathrm{NAO}^{-}$regime induce a barotropic cyclonic intergyre-gyre that carries more heat across the southern limits of the eastern subpolar gyre, hence inducing the warming.

Using hydrographic data, Skagseth and Mork (2012) suggest that heat content variability in the Norwegian Sea derives mainly from the advection of warm Atlantic Water, with little impact of surface heat fluxes. In order to determine if the 1995 warming event of the North Atlantic subpolar gyre extended to the Nordic Seas, similar heat budget calculations have been performed in this region. The domain considered was limited to the southwest by the Denmark-Scotland sills, to the southeast by a section extending across the North Sea and to the north by a section across Fram Strait and a section across the Barents Sea. Evaluation of equation 4 in this domain suggests that the 1995 warming event of the subpolar gyre barely extends to the Nordic Seas. Furthermore, the relative contributions of time-integrated surface heat fluxes and time-integrated ocean heat convergence are very different among the four model simulations analysed here, despite their common modelling framework. It is also in the Nordic Seas where simulated heat content anomalies in the top $700 \mathrm{~m}$ diverge the most from observations. This emphasizes the strong modelling efforts that remain to be accomplished in this region, in order to reproduce the complex regional processes (Drange et al. 2005). A better understanding of this misrepresentation of ocean heat content variability in the Nordic Seas might be proyided by considering the Norwegian Sea, the Iceland Plateau, the Lofoten Basin and the Greenland Basin separately, as proposed by Di Iorio and Sloan (2009).

Since the focus was laid on the variability of ocean heat content, all correlations have been performed on detrended time series. However, global average sea-surface and land temperature observations show a sharp warming trend from 1970 onward (Trenberth et al. 2007). To assess whether this global warming has an impact on the heat budget calculations performed in the present work, the linear trends in surface heat fluxes have been computed for the 1970-2010 period in the two subpolar subregions. The trends are 
weak and therefore not significant in all model simulations but LR3, which shows a significant trend of 1.72 $\mathrm{TW} /$ year in the western subpolar gyre. We conclude that the global warming trend is unlikely to impact the heat budget calculations performed in this study.

Consistently with decadal prediction experiments (Robson et al. 2012, Yeager et al. 2012 and Msadek et al. 2014), the present work confirms that in the western subpolar gyre, strong natural warming and cooling events may be predicted by monitoring surface heat fluxes in this region. A strong surface heat loss is likely to cause a delayed warming (as in 1995), and conversely for a strong surface heat gain. However, in the eastern subpolar gyre where the decadal fluctuations of ocean heat convergence drive surface heat fluxes, we expect a smaller prediction skill. As discussed above, the 1995 warming event of the eastern subpolar gyre is due to an abrupt change in ocean heat convergence that is potentially more difficult to predict. 

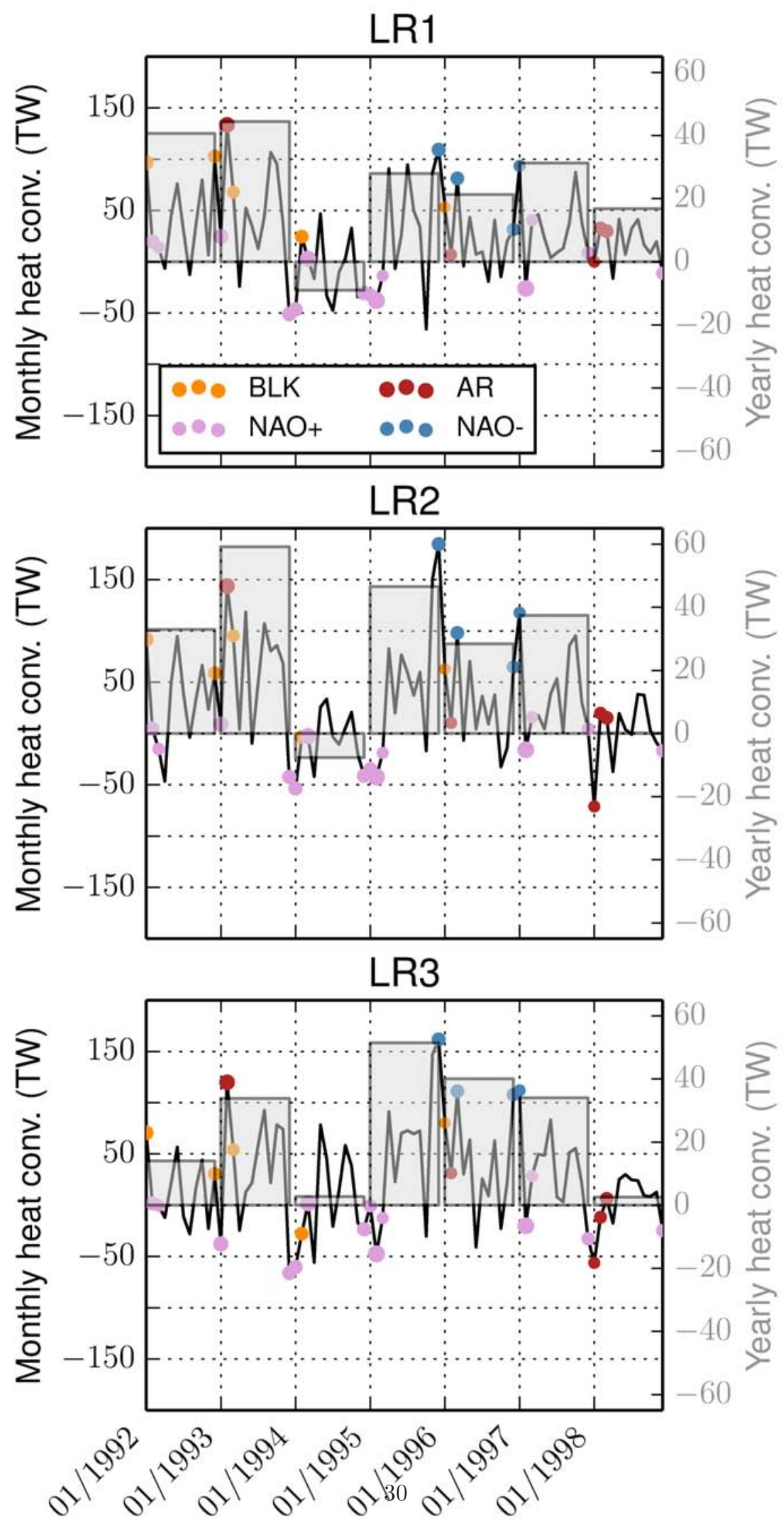

Figure 13. Monthly (black lines, left y-scale) and yearly (gray bar, right y-scale) ocean heat convergence in the eastern subpolar gyre for the three LR simulations. For each winter month, the dominant weather regime is represented by a coloured point. HR is not shown here since monthly data for this model simulation were not available. 


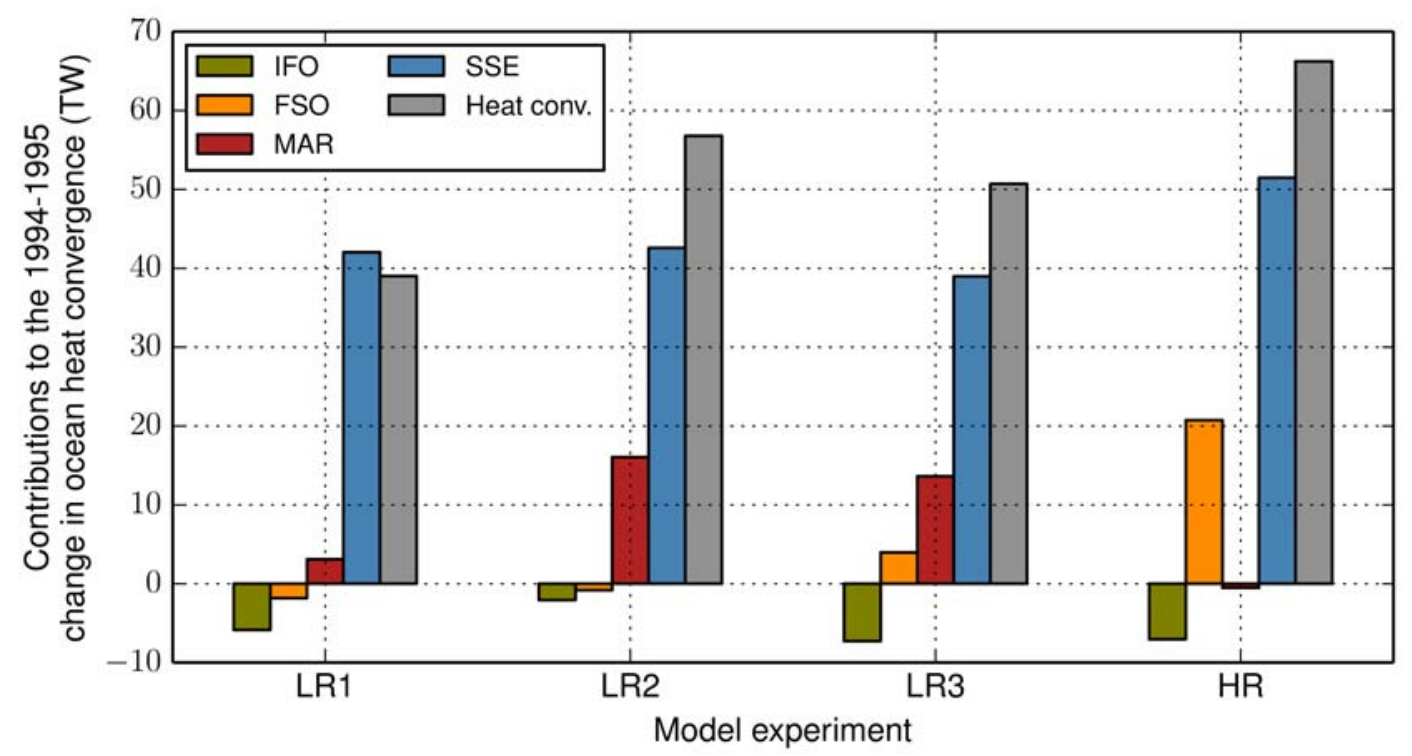

Figure 14. Contributions by the different sections to the 1994-1995 increase in ocean heat convergence in the eastern subpolar gyre in all model simulations. Values are positive when the heat transport contributes to warming the eastern subpolar gyre. 


\section{Acknowledgements}

The authors gratefully acknowledge the people of the Drakkar project who provided us with the numerical simulations. Nicolas Barrier is supported by a doctoral grant from Université de Bretagne Occidentale, Ifremer, and Europole Mer. This work has been finalized while he visited the Oceanography Department of the University of Cape Town, South Africa. Anne-Marie Treguier, Christophe Cassou and Julie Deshayes acknowledge the support of CNRS. The analysis and plots of this paper were performed with both Python and the NCAR Command Language (version 6.0.0, 2011, Boulder, Colorado, UCAR/NCAR/CISL/VETS, http://dx.doi.org/10.5065/D6WD3XH5).

\section{References}

S. Levitus, J. I. Antonov, T. P. Boyer, R. A. Locarnini, H. E. Garcia, A. V. Mishonov, Global ocean heat content 1955-2008 in light of recently revealed instrumentation problems, Geophysical Research Letters 36 (2009) L07608, doi: $\backslash$ bibinfo $\{$ doi $\}\{10$. 1029/2008GL037155\}.

N. Bindoff, J. Willebrand, V. Artale, C. A, J. Gregory, S. Gulev, K. Hanawa, C. L. Qur, S. Levitus, Y. Nojiri, C. Shum, L. Talley, A. Unnikrishnan, Observations: Oceanic Climate Change and Sea Level, Climate Change 2007: The Physical Science Basis. Contribution of Working Group I to the Fourth Assessment Report of the Intergovernmental Panel on Climate Change .

C. Cabanes, A. Cazenave, C. Le Provost, Sea Level Rise During Past 40 Years Determined from Satellite and in Situ Observations, Science 294 (5543) (2001) 840-842, doi: \bibinfo\{doi\}\{10.1126/science.1063556\}.

S. Dasgupta, B. Laplante, C. Meisner, D. Wheeler, J. Yan, The impact of sea level rise on developing countries: a comparative analysis, Climatic Change 93 (3-4) (2009) 379-388, ISSN 0165-0009, doi:〈bibinfo\{doi\}\{10.1007/s10584-008-9499-5\}.

G. Meehl, T. Stocker, W. Collins, P. Friedlingstein, A. Gaye, J. Gregory, A. Kitoh, R. Knutti, J. Murphy, A. Noda, S. Raper, I. Watterson, A. Weaver, Z.-C. Zhao, Global Climate Projections, Climate Change 2007: The Physical Science Basis. Contribution of Working Group I to the Fourth Assessment Report of the Intergovernmental Panel on Climate Change .

M. S. Lozier, S. Leadbetter, R. G. Williams, V. Roussenov, M. S. Reed, N. J. Moore, The Spatial Pattern and Mechanisms of Heat-Content Change in the North Atlantic, Science 319 (5864) (2008) 800-803, doi: \bibinfo\{doi\}\{10.1126/science.1146436\}. X. Zhai, L. Sheldon, On the North Atlantic Ocean Heat Content Change between 1955-70 and 1980-95, Journal of Climate 25 (10) (2012) 3619-3628, ISSN 0894-8755, doi: \bibinfo $\{$ doi $\}\{10.1175 / J C L I-D-11-00187.1\}$.

J. Hurrell, Decadal Trends in the North-Atlantic Oscillation: Regional Temperatures and Precipitations, Science 269 (5224) (1995) 676-679.

A. Barnston, R. Livezey, Classification, Seasonality and Persistence of Low-Frequency Atmospheric Circulation Patterns, Monthly Weather Review 115 (6) (1987) 1083-1126, doi: \bibinfo\{doi\}\{10.1175/1520-0493(1987)115〈1083:CSAPOL $>2.0 . C O$; $2\}$.

C. Cassou, M. Minvielle, L. Terray, C. Perigaud, A statistical-dynamical scheme for reconstructing ocean forcing in the Atlantic. Part I: weather regimes as predictors for ocean surface variables, Climate Dynamics 36 (1-2) (2011) 19-39, doi: \bibinfo\{doi\} $\{10.1007 /$ s00382-010-0781-7\}.

M. Bersch, North Atlantic Oscillation-induced changes of the upper layer circulation in the northern North Atlantic Ocean, Journal of Geophysical Research-Oceans 107 (3156), ISSN 0148-0227, doi:〈bibinfo\{doi\}\{10.1029/2001JC000901\}.

M. Bersch, I. Yashayaev, K. P. Koltermann, Recent changes of the thermohaline circulation in the subpolar North Atlantic, Ocean Dynamics 57 (3) (2007) 223-235, doi: \bibinfo $\{$ doi $\}\{10.1007 / \mathrm{s} 10236-007-0104-7\}$. 
A. Sarafanov, A. Falina, A. Sokov, A. Demidov, Intense warming and salinification of intermediate waters of southern origin in the eastern subpolar North Atlantic in the 1990s to mid-2000s, Journal of Geophysical Research-Oceans 113 (2008) C12022, ISSN 0148-0227, doi: \bibinfo $\{$ doi $\}\{10.1029 / 2008 J C 004975\}$.

R. Marsh, S. A. Josey, B. A. de Cuevas, L. J. Redbourn, G. D. Quartly, Mechanisms for recent warming of the North Atlantic: Insights gained with an eddy-permitting model, Journal of Geophysical Research-Oceans 113 (2008) C04031, ISSN 2169-9275, doi: \bibinfo\{doi $\}\{10.1029 / 2007 J C 004096\}$.

K. Lohmann, H. Drange, M. Bentsen, Response of the North Atlantic subpolar gyre to persistent North Atlantic Oscillation like forcing, Climate Dynamics 32 (2-3) (2009) 273-285, doi: \bibinfo\{doi $\}\{10.1007 /$ s00382-008-0467-6 .

J. P. Grist, S. A. Josey, R. Marsh, S. A. Good, A. C. Coward, B. A. de Cuevas, S. G. Alderson, A. L. New, G. Madec, The roles of surface heat flux and ocean heat transport convergence in determining Atlantic Ocean temperature variability, Ocean Dynamics 60 (4) (2010) 771-790, doi: \bibinfo\{doi $\}\{10.1007 / \mathrm{s} 10236-010-0292-4\}$.

D. Desbruyeres, H. Mercier, V. Thierry, On the mechanisms behind decadal heat content changes in the eastern subpolar gyre, Progress in Oceanography, in press doi: \bibinfo $\{$ doi $\}\{10.1016 /$ j.pocean.2014.02.005 $\}$.

S. Yeager, A. Karspeck, G. Danabasoglu, J. Tribbia, H. Teng, A Decadal Prediction Case Study: Late Twentieth-Century North Atlantic ocean heat content, Journal of Climate 25 (15) (2012) 5173-5189, doi: \bibinfo\{doi\}\{10.1175/JCLI-D-11-00595.1\}. J. Robson, R. Sutton, K. Lohmann, D. Smith, M. D. Palmer, Causes of the Rapid Warming of the North Atlantic Ocean in the Mid-1990s, Journal of Climate 25 (12) (2012) 4116-4134, doi: \bibinfo\{doi\}\{10.1175/JCLI-D-11-00443.1\}.

R. Msadek, T. Delworth, A. Rosati, W. Anderson, G. Vecchi, Y.-S. Chang, K. Dixon, R. Gudgel, B. Stern, A. Wittenberg, X. Yang, F. Zeng, R. Zhang, S. Zhang, Predicting a decadal shift in North Atlantic climate variability using the GFDL forecast system, Journal of Climate 27 (2014) 6472-6496, doi: \bibinfo\{doi\}\{10.1175/JCLI-D-13-00476.1\}.

H. Hátún, A. B. Sandø, H. Drange, B. Hansen, H. Valdimarsson, Influence of the Atlantic Subpolar Gyre on the Thermohaline Circulation, Science 309 (5742) (2005) 1841-1844, doi: \bibinfo\{doi $\}\{10.1126 /$ science.1114777\}.

S. Häkkinen, P. B. Rhines, D. L. Worthen, Atmospheric Blocking and Atlantic Multidecadal Ocean Variability, Science 334 (6056) (2011a) 655-659, doi: \bibinfo $\{$ doi $\}\{10.1126 /$ science. 1205683$\}$.

S. Häkkinen, P. B. Rhines, D. L. Worthen, Warm and saline events embedded in the meridional circulation of the northern North Atlantic, Journal of Geophysical Research-Oceans 116 (2011b) C03006, doi: \bibinfo\{doi $\}\{10.1029 / 2010 J C 006275\}$.

J. Deshayes, C. Frankignoul, Simulated Variability of the Circulation in the North Atlantic from 1953 to 2003 , Journal of Climate 21 (19) (2008) 4919-4933, ISSN 0894-8755, doi: \bibinfo $\{$ doi $\}\{\{10.1175 / 2008 J C L I 1882.1\}\}$.

K. E. Taylor, R. J. Stouffer, G. A. Meehl, An Overview of CMIP5 and the Experiment Design, Bulletin of the American Meteorological Society 93 (4) (2012) 485-498, doi: \bibinfo\{doi\}\{10.1175/BAMS-D-11-00094.1\}.

J. Deshayes, A. M. Treguier, B. Barnier, A. Lecointre, J. Le Sommer, J. M. Molines, T. Penduff, R. Bourdalle-Badie, Y. Drillet, G. Garric, R. Benshila, G. Madec, A. Biastoch, C. W. Boening, M. Scheinert, A. C. Coward, J. J. M. Hirschi, Oceanic hindcast simulations at high resolution suggest that the Atlantic MOC is bistable, Geophysical Research Letters 40 (12) (2013) 3069-3073, ISSN 0094-8276, doi: \bibinfo $\{$ doi $\}\{10.1002 / \operatorname{grl} .50534\}$.

V. Thierry, E. de Boisseson, H. Mercier, Interannual variability of the Subpolar Mode Water properties over the Reykjanes Ridge during 1990-2006, Journal of Geophysical Research-Oceans 113 (2008) C04016, ISSN 2169-9275, doi: \bibinfo\{doi\}\{10. 1029/2007JC004443\}.

C. Cassou, L. Terray, J. Hurrell, C. Deser, North Atlantic Winter Climate Regimes: Spatial Asymmetry, Stationarity with Time, and Oceanic Forcing, Journal of Climate 17 (5) (2004) 1055-1068, doi: \bibinfo\{doi\}\{10.1175/1520-0442(2004)017〈1055: NAWCRS $>2.0 . \mathrm{CO} ; 2\}$.

N. Barrier, C. Cassou, J. Deshayes, A.-M. Treguier, Response of North Atlantic Ocean Circulation to Atmospheric Weather Regimes, Journal of Physical Oceanography 44 (2014) 179-201, doi:\bibinfo\{doi\}\{10.1175/JPO-D-12-0217.1\}.

G. Madec, NEMO ocean engine, note du Pole de modélisation, Institut Pierre-Simon Laplace (IPSL), 2008. 
B. Barnier, G. Madec, T. Penduff, J.-M. Molines, A.-M. Treguier, J. Le Sommer, A. Beckmann, A. Biastoch, C. Boening, J. Dengg, C. Derval, E. Durand, S. Gulev, E. Remy, C. Talandier, S. Theetten, M. Maltrud, J. McClean, B. De Cuevas, Impact of partial steps and momentum advection schemes in a global ocean circulation model at eddy-permitting resolution, Ocean Dynamics 56 (5-6) (2006) 543-567, doi: \bibinfo\{doi\}\{10.1007/s10236-006-0082-1\}.

S. Levitus, T. Boyer, M. Conkright, J. O’Brien, T. Antonov, C. Stephens, S. L., J. D., R. Gelfeld, NOAA Atlas NESDIS 18 and World Ocean Database 1998, NOAA Atlas NESDIS 18 and World Ocean Database 1998 .

A. M. Treguier, M. H. England, S. R. Rintoul, G. Madec, J. Le Sommer, J. M. Molines, Southern Ocean overturning across streamlines in an eddying simulation of the Antarctic Circumpolar Current, Ocean Science 3 (4) (2007) 491-507, ISSN 1812-0784.

C. Lique, A. M. Treguier, B. Blanke, N. Grima, On the origins of water masses exported along both sides of Greenland: A Lagrangian model analysis, Journal of Geophysical Research-Oceans 115 (2010) C05019, ISSN 2169-9275, doi: \bibinfo\{doi\} $\{\{10.1029 / 2009 \mathrm{JC} 005316\}\}$.

L. Brodeau, B. Barnier, A.-M. Treguier, T. Penduff, S. Gulev, An ERA40-based atmospheric forcing for global ocean circulation models, Ocean Modelling 31 (3-4) (2010) 88-104, ISSN 1463-5003, doi: \bibinfo\{doi\}\{10.1016/j.ocemod.2009.10.005\} .

S. Uppala, P. Kallberg, A. Simmons, U. Andrae, V. Bechtold, M. Fiorino, J. Gibson, J. Haseler, A. Hernandez, G. Kelly, X. Li, K. Onogi, S. Saarinen, N. Sokka, R. Allan, E. Andersson, K. Arpe, M. Balmaseda, A. Beljaars, L. Van De Berg, J. Bidlot, N. Bormann, S. Caires, F. Chevallier, A. Dethof, M. Dragosavac, M. Fisher, M. Fuentes, S. Hagemann, E. Holm, B. Hoskins, L. Isaksen, P. Janssen, R. Jenne, A. McNally, J. Mahfouf, J. Morcrette, N. Rayner, R. Saunders, P. Simon, A. Sterl, K. Trenberth, A. Untch, D. Vasiljevic, P. Viterbo, J. Woollen, The ERA-40 re-analysis, Quaterly Journal of the Royal Meteorological Society 131 (612, Part b) (2005) 2961-3012, doi: \bibinfo\{doi\}\{10.1256/qj.04.176\}.

W. G. Large, S. G. Yeager, The global climatology of an interannually varying air-sea flux data set, Climate Dynamics 33 (2009) 341-364, doi: \bibinfo $\{$ doi $\}\{10.1007 /$ s00382-008-0441-3\}.

C. Lique, M. Steele, Seasonal to decadal variability of Arctic Ocean heat content: A model-based analysis and implications for autonomous observing systems, Journal of Geophysical Research-Oceans 118 (4) (2013) 1673-1695, ISSN 2169-9275, doi: \bibinfo $\{$ doi $\}\{10.1002 /$ jgrc. 20127$\}$.

J.-M. Molines, B. Barnier, T. Penduff, A.-M. Treguier, J. Le Sommer, ORCA12.L46 climatological and interannual simulations forced with DFS4.4: GJM02 and MJM88, Tech. Rep., Experiment report GDRI-DRAKKAR, URL http: //www.drakkar-ocean.eu/publications/reports/orca12_reference_experiments_2014, 2014.

D. Dee, S. Uppala, A. Simmons, P. Berrisford, P. Poli, S. Kobayashi, U. Andrae, M. Balmaseda, G. Balsamo, P. Bauer, et al., The ERA-Interim reanalysis: Configuration and performance of the data assimilation system, Quarterly Journal of the Royal Meteorological Society 137 (656) (2011) 553-597, doi: \bibinfo\{doi $\}\{10.1002 /$ qj.828\}.

R. Dussin, J.-M. Molines, B. Barnier, Definition of the interannual experiment ORCA025.L75-GRD100, 19582010, Tech. Rep., MEOM-LEGI-CNRS-LEGI-DRA, URL http://www.drakkar-ocean.eu/publications/reports/ orca025-grd100-report-dussin, 2012.

E. Kalnay, M. Kanamitsu, R. Kistler, W. Collins, D. Deaven, L. Gandin, M. Iredell, S. Saha, G. White, J. Woollen, Y. Zhu, M. Chelliah, W. Ebisuzaki, W. Higgins, J. Janowiak, K. Mo, C. Ropelewski, J. Wang, A. Leetmaa, R. Reynolds, R. Jenne, D. Joseph, The NCEP/NCAR 40-Year Reanalysis Project, Bulletin of the American Meteorological Society 77 (3) (1996) 437-471, doi: \bibinfo $\{$ doi $\}\{10.1175 / 1520-0477(1996) 077\langle 0437: T N Y R P\rangle 2.0 . C O ; 2\}$.

H. Mercier, P. Lherminier, F. Sarafanov, F. Gaillard, D. Desbruyeres, A. Falina, B. Ferron, T. Huck, V. Thierry, Variability of the meridional overturning circulation at the Greenland-Portugal OVIDE section from 1993 to 2010 , Progress in Oceanography, in press doi: \bibinfo $\{$ doi $\}\{10.1016 /$ j.pocean.2013.11.001\}.

B. Hansen, S. Østerhus, North Atlantic-Nordic Seas exchanges, Progress in Oceanography 45 (2) (2000) 109-208, doi: $\backslash$ bibinfo\{doi $\}\{10.1016 /$ S0079-6611(99)00052-X\}. 
G. Roullet, G. Madec, Salt conservation, free surface, and varying levels: A new formulation for ocean general circulation models, Journal of Geophysical Research-Oceans 105 (C10) (2000) 23927-23942, doi: \bibinfo\{doi\}\{10.1029/2000JC900089\}.

J. Deshayes, R. Curry, R. Msadek, CMIP5 Model Intercomparison of Freshwater Budget and Circulation in the North Atlantic, Journal of Climate 27 (9) (2014) 3298-3317, ISSN 0894-8755, doi: \bibinfo\{doi\}\{10.1175/JCLI-D-12-00700.1\}.

A. Ganachaud, C. Wunsch, Large-Scale Ocean Heat and Freshwater Transports during the World Ocean Circulation Experiment, Journal of Climate 16 (4) (2003) 696-705, doi: \bibinfo\{doi\}\{10.1175/1520-0442(2003)016<0696:LSOHAF $>2.0 . \mathrm{CO} ; 2\}$.

R. Lumpkin, K. Speer, Global Ocean Meridional Overturning, Journal of Physical Oceanography 37 (10) (2007) 2550-2562, doi: \bibinfo $\{$ doi $\}\{10.1175 / J P O 3130.1\}$.

Y. Aksenov, S. Bacon, A. C. Coward, A. Nurser, The North Atlantic inflow to the Arctic Ocean: High-resolution model study, Journal of Marine Systems 79 (1) (2010) 1-22, doi: \bibinfo\{doi\}\{10.1016/j.jmarsys.2009.05.003\}.

S. Østerhus, W. R. Turrell, S. Jónsson, B. Hansen, Measured volume, heat, and salt fluxes from the Atlantic to the Arctic Mediterranean, Geophysical Research Letters 32 (7) (2005) L07603, doi: \bibinfo\{doi\}\{10.1029/2004GL022188\}.

B. Ingleby, M. Huddleston, Quality control of ocean temperature and salinity profiles - Historical and real-time data, Journal of Marine Systems 65 (1) (2007) 158-175, doi: \bibinfo\{doi\}\{10.1016/j.jmarsys.2005.11.019\}.

R. Locarnini, J. Mishonov, A.V.and Antonov, T. Boyer, H. Garcia, World Ocean Atlas 2009, Volume 1: Temperature, NOAA Atlas NESDIS 68 .

P. Michelangi, R. Vautard, B. Legras, Weather Regimes: Recurrence and Quasi-Stationarity, Journal of Atmospheric Sciences 52 (8) (1995) 1237-1256, doi: \bibinfo\{doi $\}\{10.1175 / 1520-0469(1995) 052\langle 1237:$ WRRAQS $\rangle$ 2.0.CO;2\}.

N. Barrier, A.-M. Treguier, C. Cassou, J. Deshayes, Impact of the winter North-Atlantic weather regimes on subtropical sea-surface height variability, Climate Dynamics 41 (5-6) (2013) 1159-1171, doi: \bibinfo\{doi\}\{10.1007/s00382-012-1578-7\}.

R. Vautard, Multiple Weather Regimes over the North-Atlantic. Analysis of Precursors and Successors, Monthly Weather Review 118 (10) (1990) 2056-2081.

C. Bretherton, M. Widmann, V. Dymnikov, J. Wallace, I. Blade, The Effective Number of Spatial Degrees of Freedom of a Time-Varying Field, Journal of Climate 12 (7) (1999) 1990-2009, doi: \bibinfo\{doi $\}\{10.1175 / 1520-0442(1999) 012\langle 1990$ : TENOSD $>2.0 . \mathrm{CO} ; 2\}$.

H. R. Langehaug, I. Medhaug, T. Eldevik, O. H. Otterå, Arctic/Atlantic Exchanges via the Subpolar Gyre, Journal of Climate 25 (7) (2012) 2421-2439, doi: \bibinfo $\{$ doi $\}\{10.1175 /$ JCLI-D-11-00085.1 $\}$.

Y. Ruprich-Robert, C. Cassou, Combined influences of seasonal East Atlantic Pattern and North Atlantic Oscillation to excite Atlantic multidecadal variability in a climate model, Climate Dynamics (2013) 1-25doi: $\backslash$ bibinfo\{doi $\}\{10.1007 /$ s00382-014-2176-7\}.

J. Nilsen, Y. Gao, H. Drange, T. Furevik, M. Bentsen, Simulated North Atlantic-Nordic Seas water mass exchanges in an isopycnic coordinate OGCM, Geophysical Research Letters 30 (10) (2003) 1536, doi: \bibinfo\{doi $\}\{10.1029 / 2002$ GL016597\} .

I. Medhaug, H. R. Langehaug, T. Eldevik, T. Furevik, M. Bentsen, Mechanisms for decadal scale variability in a simulated Atlantic meridional overturning circulation, Climate Dynamics 39 (1-2) (2012) 77-93, ISSN 0930-7575, doi: \bibinfo\{doi\}\{10. $1007 / \mathrm{s} 00382-011-1124-\mathrm{z}\}$.

J. Marshall, H. Johnson, J. Goodman, A study of the Interaction of the North Atlantic Oscillation with Ocean Circulation, Journal of Climate 14 (7) (2001) 1399-1421, doi: \bibinfo\{doi\}\{10.1175/1520-0442(2001)014<1399:ASOTIO $\rangle$ 2.0.CO;2\}.

C. Eden, J. Willebrand, Mechanism of Interannual to Decadal Variability of the North Atlantic Circulation, Journal of Climate 14 (10) (2001) 2266-2280, doi: \bibinfo\{doi\}\{10.1175/1520-0442(2001)014〈2266:MOITDV $\rangle 2.0 . \mathrm{CO} ; 2\}$.

C. Herbaut, M.-N. Houssais, Response of the eastern North Atlantic subpolar gyre to the North Atlantic Oscillation, Geophysical Research Letters 36 (2009) L17607, ISSN 0094-8276, doi: \bibinfo\{doi\}\{10.1029/2009GL039090\}.

C. Mauritzen, S. Hjøllo, A. B. Sandø, Passive tracers and active dynamics: A model study of hydrography and circulation in the northern North Atlantic, Journal of Geophysical Research: Oceans 111 (2006) C08014, doi: $\backslash$ bibinfo\{doi\}\{10.1029/ 
2005JC003252\}.

C. Frankignoul, J. Deshayes, R. Curry, The role of salinity in the decadal variability of the North Atlantic meridional overturning circulation, Climate dynamics 33 (6) (2009) 777-793, doi: \bibinfo $\{$ doi $\}\{10.1007 /$ s00382-008-0523-2\}.

I. Yashayaev, Hydrographic changes in the Labrador Sea, 1960-2005, Progress in Oceanography 73 (3) (2007) 242-276, doi: $\backslash$ bibinfo\{doi\}\{10.1016/j.pocean.2007.09.001\}.

J. Lazier, R. Hendry, A. Clarke, I. Yashayaev, P. Rhines, Convection and restratification in the Labrador Sea, 1990-2000, DeepSea Research Part I-Oceanographic Research Papers 49 (10) (2002) 1819-1835, doi:〈bibinfo\{doi\}\{10.1016/S0967-0637(02) 00064-X\}.

O. Skagseth, K. A. Mork, Heat content in the Norwegian Sea, 1995-2010, ICES Journal Of Marine Science 69 (5) (2012) 826-832, ISSN 1054-3139, doi: \bibinfo\{doi $\{$ 10.1093/icesjms/fss026 $\}$.

H. Drange, R. Gerdes, Y. Gao, M. Karcher, F. Kauker, M. Bentsen, Ocean general circulation modelling of the Nordic Seas, in: The Nordic Seas: An Integrated Perspective, American Geophysical Union, 199-219, 2005.

D. Di Iorio, C. Sloan, Upper ocean heat content in the Nordic Seas, Journal of Geophysical Research-Oceans 114 (2009) C04017, ISSN 2169-9275, doi: \bibinfo\{doi\} \{10.1029/2007JC004674\}.

K. Trenberth, P. Jones, P. Ambenje, R. Bojariu, D. Easterling, T. Klein, J. Renwick, et al., Observations: surface and atmospheric climate change, Climate Change 2007: The Physical Science Basis. Contribution of Working Group I to the Fourth Assessment Report of the Intergovernmental Panel on Climate Change. 